Supporting Information

\title{
Promoting Dual-Targeting Anticancer Effect by Regulating the Dynamic Intracellular Self-Assembly
}

Shijin Zhang, and Ye Zhang*

Bioinspired Soft Matter Unit, Okinawa Institute of Science and Technology Graduate University, 1919-1 Tancha, Onna Son, Okinawa 904-0495, Japan.

*ye.zhang@oist.jp 


\section{Table of Contents}

Experimental Procedures (Page 3)

Synthesis (Page 3)

Materials and instruments (Page 3$)$

Coumarin 466 (Page 3)

Scheme S1 (Page 3)

(Coumarin 466)-FFK(Boc) (Page 3)

Scheme S2 (Page 4)

(Coumarin 466)-ffk(Boc) (Page 4)

Scheme S3 (Page 4)

(Coumarin 466)-FFK (Page 5)

Scheme S4 (Page 5)

(Coumarin 466)-ffk (Page 6)

Scheme S5 (Page 6)

(Coumarin 466)-FFK(Boc)-ethylene glycol (Page 6)

Scheme S6 (Page 6)

(Coumarin 466)-ffk(Boc)-ethylene glycol (Page 6)

Scheme 57 (Page 7$)$

(Coumarin 466)-FFK(Boc)-ethylene glycol-Cbl (Page 7$)$

Scheme S8 (Page 7$)$

(Coumarin 466)-ffk(Boc)-ethylene glycol-Cbl (Page 7)

Scheme S9 (Page 7$)$

SJC-1 (Page 8)

Scheme S10 (Page 8)

SJC-2 (Page 8)

Scheme S11 (Page 8)

Coumarin 466)-FFK-Ace (Page 9 )

Scheme S12 (Page 9)

(Coumarin 466)-ffk-Ace (Page 9)

Scheme S13 (Page 9)

Figure S1 (Page 10)

Figure S2 (Page 10)

CES catalyzed hydrolysis (Page 11)

In buffer

Figure S3 (Page 11)

Intracellular hydrolysis analysis

Figure S4 (Page 12)

UV-Vis absorption and fluorescence emission spectroscopy

Figure S5 (Page 12)

Confocal microscopy imaging

Figure S6 (Page 13)

Flow cytometry analysis of cell cycle distribution

Figure S7 (Page 14)

Figure S8 (Page 14)

Figure S9 (Page 14)

Western blotting

Figure S10 (Page 15)

Figure S11 (Page 16)

Chemical structure characterization

Figure S12 (Page 17)

Figure S13 (Page 17)

Figure S14 (Page 18)

Figure S15 (Page 18)

Figure S16 (Page 19)

Figure S17 (Page 19)

Figure S18 (Page 20)

Figure $\mathrm{S} 19$ (Page 20)

Figure S20 (Page 21)

Figure S21 (Page 21)

Figure S22 (Page 22)

Figure S23 (Page 22)

Figure S24 (Page 23)

Figure S25 (Page 23)

Figure S26 (Page 24)

Figure S27 (Page 24)

Figure S28 (Page 25)

Figure S29 (Page 25) 


\section{Experimental Procedures}

\section{Synthesis}

Materials and instruments: Fmoc-Amino acid and 2-chlorotrityl chloride resin were purchased from GL Biochem (Shanghai, China); dimethylformamide (DMF), dichloromethane (DCM), tetrahydrofuran (THF), methanol (MeOH), ethanol (EtOH), hexane (Hex), 2,2,2trifluoroethanol (TFE, 99.0\%), acetic anhydride (95.0\%), piperidine (99.0\%), acetonitrile (HPLC grade) were purchased from Nacalai Tesque Inc., Japan; N,N-diisopropylethylamine (DIEA), 2-(1H-benzotriazol-1-yl)-1,1,3,3-tetramethyluronium hexafluorophosphate (HBTU) (98.0\%), trifluoroacetic acid (TFA, 99.0\%), N-(3-dimethylaminopropyl)- $N$-ethylcarbodiimide hydrochloride (EDCI, 98.0\%), 4dimethylaminopyridine (DMAP, 99.0\%), meldrum's acid (98.0\%), ethylene glycol anhydrous (99.8\%) were purchased from Sigma Aldrich. Piperidinum acetate (98.0\%), 4-(diethylamino)salicylaldehyde (98\%), pyridine (99.0\%) were obtained from Tokyo Chemistry Industry (TCI). Chlorambucil (98.0\%) was purchased from LKT Laboratories, Inc. Organic solvents were dehydrated using solvent purification system. HPLC purification was performed on a Agilent 1260 Infinity Preparative Pump with Agilent 1260 Infinity Diode Array Detector. A $19 \mathrm{~mm} \times 150 \mathrm{~mm}$ XBridge ${ }^{\circledR}$ Peptide BEH C18 column (Waters) was used for semi-preparative HPLC purification. Mass spectra were obtained through a Thermo LTQ-ETD mass spectrometer (ESI-MS). ${ }^{1} \mathrm{H}$ and ${ }^{13} \mathrm{C}$ nuclear magnetic resonance spectroscopy $\left({ }^{1} \mathrm{H}\right.$ NMR and ${ }^{13} \mathrm{C}$ NMR) spectra were recorded using a Bruker AVANCE $400 \mathrm{~N}$ (400 MHz and 101MHz, respectively) spectrometer with $\mathrm{CDCl}_{3}$ or DMSO- $d_{6}$ as solvents.

\section{Coumarin 466:}<smiles>CCN(CC)c1ccc(C=O)c(O)c1</smiles><smiles>CCN(CC)c1ccc2cc(C(=O)O)c(=O)oc2c1</smiles>

Coumarin 466

Scheme S1. Synthesis of compound Coumarin 466.

Meldrum's acid $(3.60 \mathrm{~g}, 25 \mathrm{mmol})$, 4-(diethylamino)salicylaldehyde $(4.83 \mathrm{~g}, 25 \mathrm{mmol})$, and piperidinum acetate $(73 \mathrm{mg}, 0.5 \mathrm{mmol})$ were transferred into a $100 \mathrm{~mL}$ round-bottom flask, $30 \mathrm{~mL}$ ethanol was added into the mixture and refluxed overnight. After cooling down, precipitate was filtered and washed with cooled down ethanol. The obtained orange target compound was dried in $50{ }^{\circ} \mathrm{C}$ oven for 3 hours, yield: $83.2 \%$

${ }^{1} \mathrm{HNMR}\left(400 \mathrm{MHz}, \mathrm{CDCl}_{3}\right) \delta=8.63(\mathrm{~d}, J=0.6 \mathrm{~Hz}, 1 \mathrm{H}), 7.44(\mathrm{~d}, J=9.1 \mathrm{~Hz}, 1 \mathrm{H}), 6.71$ (dd, J=9.1, 2.5 Hz, 1H), 6.53 (dd, J=2.4, $0.4 \mathrm{~Hz}$, $1 \mathrm{H}), 3.48$ (q, J=7.2 Hz, 4H), 1.25 (t, J=7.2 Hz, 6H).ppm.

MS: calculated for $\mathrm{C}_{14} \mathrm{H}_{25} \mathrm{NO}_{4}$ is 261.1001 , found 284.0886, [M $\left.+\mathrm{Na}\right]^{+}$.

\section{(Coumarin 466)-FFK(Boc):}



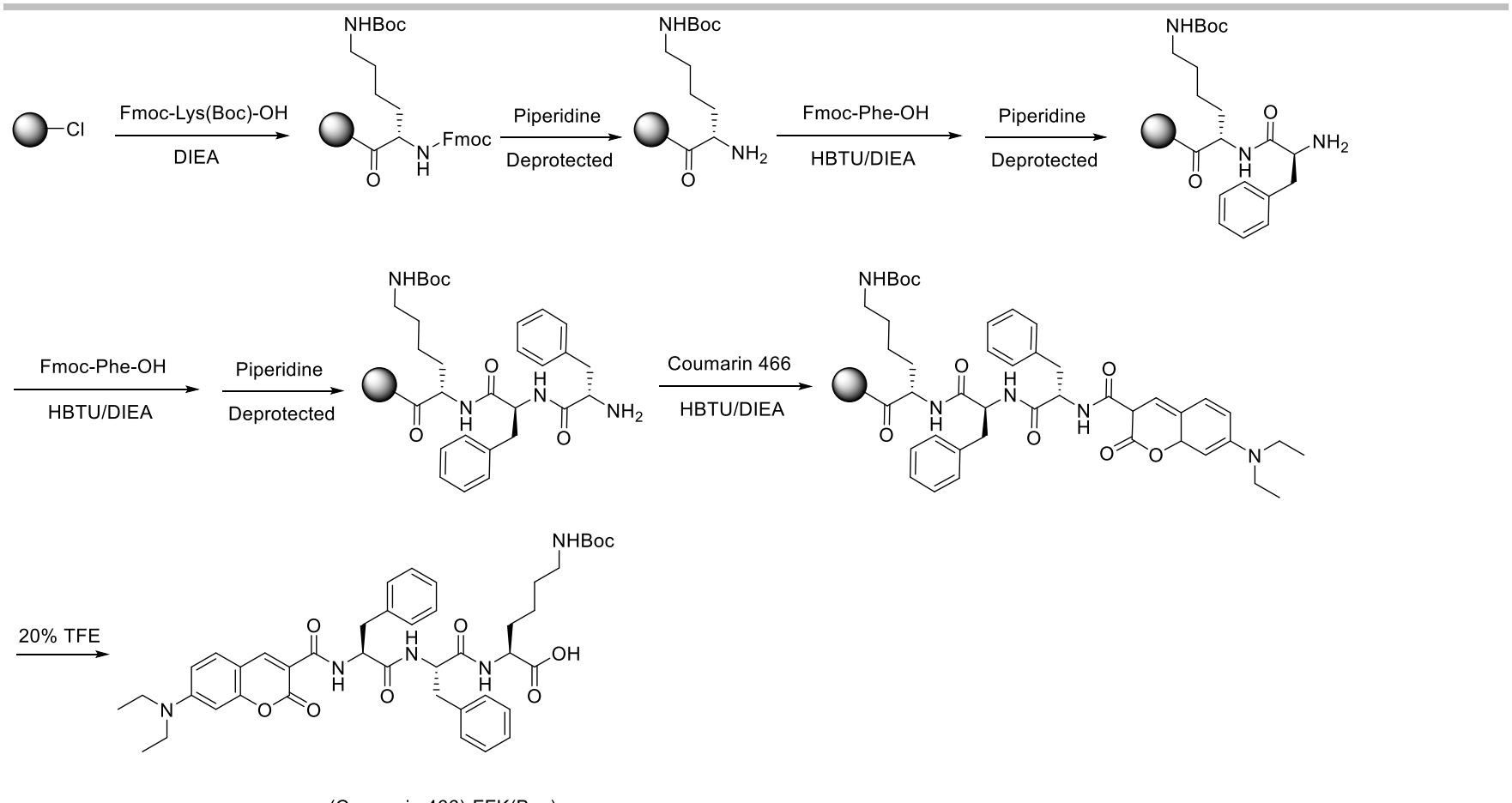

(Coumarin 466)-FFK(Boc)

Scheme S2. Synthesis of compound (Coumarin 466)-FFK(Boc).

(Coumarin 466)-FFK(Boc) was obtained via solid phase peptide synthesis (SPPS). 2-Chlorotrityl chloride resin (2.0 g, $2 \mathrm{mmol})$ was swelled in anhydrous DCM for $20 \mathrm{~min}$, further washed by anhydrous DMF for 5 times. L-Fmoc-Lys(Boc)-OH (2.34g, $5 \mathrm{mmol})$ dissolved in anhydrous DMF was conjugated to resin with DIEA in $30 \mathrm{~min}$. Then washed with anhydrous DMF for 3 times, unreacted sites in the resin were blocked with DCM/MeOH/DIEA (80:15:5) for $10 \mathrm{~min}$ and repeated once more, the resin was washed by anhydrous DMF for 5 times. Then piperidine solution (20\% in DMF) was added into reaction for 30 min to remove the Fmoc protecting group on the amino acid. We carried out the peptide elongation according to standard SPPS protocol to get the desired compound. (Coumarin 466)-FFK(Boc) was cleaved off the resin using $20 \%$ TFE for $2 \mathrm{~h}$. After removing the solvent, anhydrous ether was added into the concentrated product and yellow precipitation of (Coumarin 466)-FFK(Boc) was obtained, yield: $88.3 \%$.

${ }^{1} \mathrm{H}$ NMR $(400 \mathrm{MHz}$, DMSO-d6) $\delta=8.86(\mathrm{~d}, J=7.7,1 \mathrm{H}), 8.59(\mathrm{~s}, 1 \mathrm{H}), 8.38(\mathrm{~d}, J=8.4,1 \mathrm{H}), 8.25(\mathrm{~d}, J=7.4,1 \mathrm{H}), 7.66(\mathrm{~d}, J=9.0,1 \mathrm{H}), 7.34$ - $7.06(\mathrm{~m}, 10 \mathrm{H}), 6.79(\mathrm{~d}, \mathrm{~J}=7.4,2 \mathrm{H}), 6.61(\mathrm{~s}, 1 \mathrm{H}), 4.82-4.54(\mathrm{~m}, 2 \mathrm{H}), 4.19(\mathrm{~d}, \mathrm{~J}=5.4,1 \mathrm{H}), 3.48(\mathrm{~d}, \mathrm{~J}=6.9,4 \mathrm{H}), 3.33(\mathrm{~s}, 2 \mathrm{H}), 2.96-$ 2.78(m, 4H), $1.79-1.59(m, 2 H), 1.45-1.27(m, 13 H), 1.14(t, J=6.9,6 H)$.

MS: calculated for $\mathrm{C}_{43} \mathrm{H}_{53} \mathrm{~N}_{5} \mathrm{O}_{9}$ is 783.3843 , found 782.4097, [M - H]

\section{(Coumarin 466)-ffk(Boc):}<smiles>CCN(CC)c1ccc2cc(C(=O)NC(Cc3ccccc3)C(=O)NC(Cc3ccccc3)C(=O)N[C@@H](CCCCNC(C)(C)C)C(=O)O)c(=O)oc2c1</smiles>

(Coumarin 466)-ffk(Boc) 
compound (Coumarin 466)-ffk(Boc) was synthesized using the same protocol as compound (Coumarin 466)-FFK(Boc), just changed the L-Fmoc-Amino acids to D-Fmoc-Amino acids. The yield was $83.6 \%$.

${ }^{1} \mathrm{H}$ NMR $(400 \mathrm{MHz}$, DMSO-d6) $\delta=8.86(\mathrm{~d}, \mathrm{~J}=7.7,1 \mathrm{H}), 8.59(\mathrm{~s}, 1 \mathrm{H}), 8.37(\mathrm{~d}, \mathrm{~J}=8.4,1 \mathrm{H}), 8.26(\mathrm{~d}, \mathrm{~J}=7.5,1 \mathrm{H}), 7.66(\mathrm{~d}, \mathrm{~J}=9.0,1 \mathrm{H}), 7.37$ $-7.01(\mathrm{~m}, 10 \mathrm{H}), 6.79(\mathrm{~d}, J=7.5,2 \mathrm{H}), 6.60(\mathrm{~s}, 1 \mathrm{H}), 4.68(\mathrm{dd}, J=47.2,4.2,2 \mathrm{H}), 4.19$ (d, J=5.5, 1H), 3.48 (dd, J=13.4, $6.5,4 \mathrm{H}), 3.33$ (s, $2 \mathrm{H}), 2.94-2.75(\mathrm{~m}, 4 \mathrm{H}), 1.74-1.57(\mathrm{~m}, 2 \mathrm{H}), 1.45-1.28(\mathrm{~m}, 13 \mathrm{H}), 1.13(\mathrm{t}, \mathrm{J}=6.8,6 \mathrm{H})$.

MS: calculated for $\mathrm{C}_{43} \mathrm{H}_{53} \mathrm{~N}_{5} \mathrm{O}_{9}$ is 783.3843, found 782.4092, [M - H]'.

\section{(Coumarin 466)-FFK:}
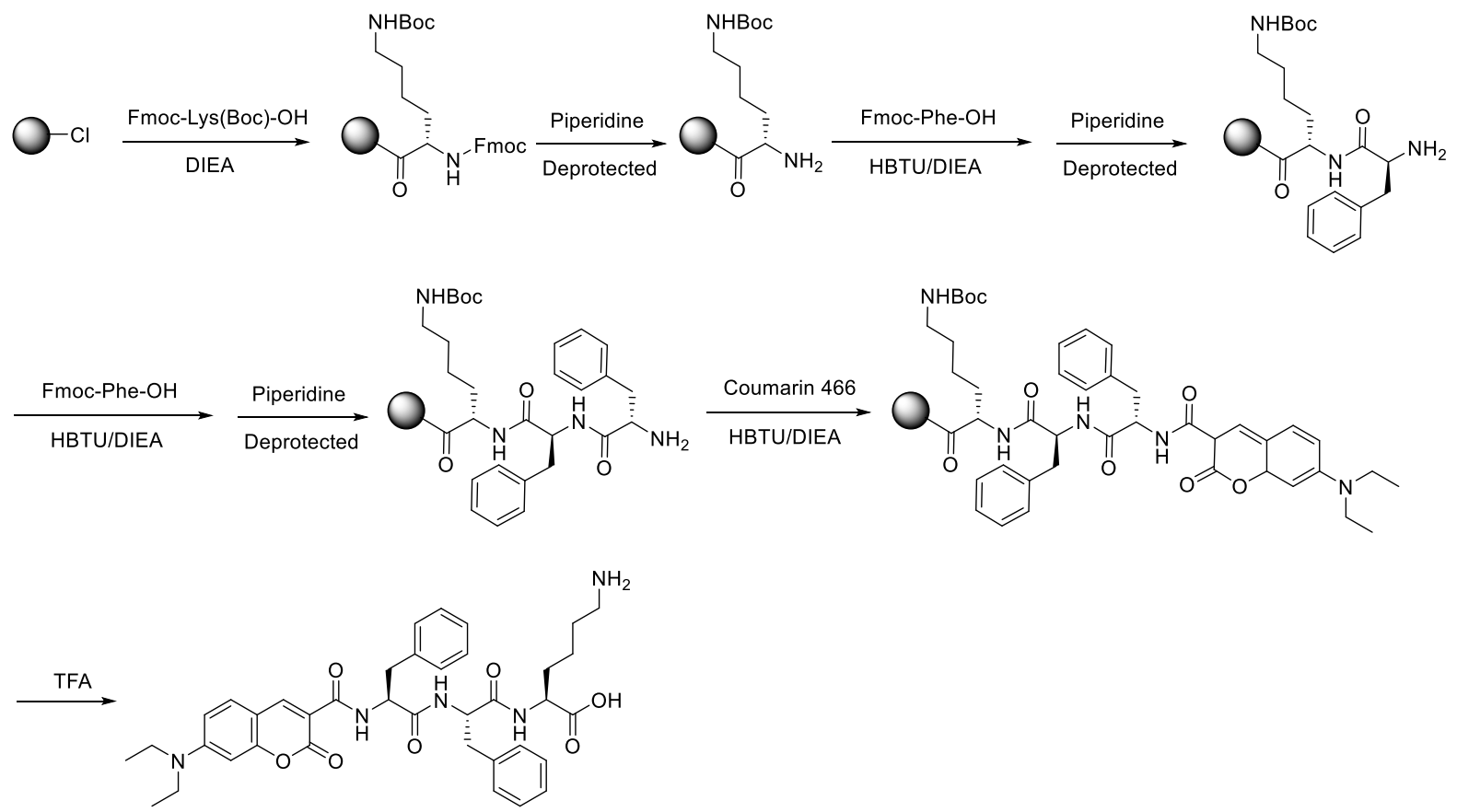

(Coumarin 466)-FFK

Scheme S4. Synthesis of compound (Coumarin 466)-FFK.

Compound (Coumarin 466)-FFK was obtained via solid phase peptide synthesis (SPPS). 2-Chlorotrityl chloride resin (2.0 g, 2mmol) was swelled in anhydrous DCM for $20 \mathrm{~min}$, L-Fmoc-Lys(Boc)-OH (2.34g, 5mmol) dissolved in anhydrous DMF was conjugated to resin with DIEA in 30 min. Then washed with anhydrous DMF for 3 times, unreacted sites in the resin were blocked with DCM/MeOH/DIEA (80:15:5) for 20 min and washed by anhydrous DMF for 5 times. Then piperidine solution (20\% in DMF) was added into reaction for 30 min to remove the Fmoc protecting group on the amino acid. We carried out the peptide elongation according to standard SPPS protocol to get the desired compound. (Coumarin 466)-FFK was cleaved off the resin using TFA for $2 \mathrm{~h}$. After removing the solvent, anhydrous ether was added into the concentrated product and yellow precipitation of (Coumarin 466)-FFK was obtained, yield: $90.2 \%$.

${ }^{1} \mathrm{H}$ NMR $(400 \mathrm{MHz}$, DMSO-d6) $\delta=8.81(\mathrm{~d}, J=7.8,1 \mathrm{H}), 8.51(\mathrm{~s}, 1 \mathrm{H}), 8.32(\mathrm{dd}, J=32.7,7.9,2 \mathrm{H}), 7.58(\mathrm{~d}, J=9.0,1 \mathrm{H}), 7.33-7.01(\mathrm{~m}$, $10 \mathrm{H}), 6.71(\mathrm{~d}, \mathrm{~J}=9.1,1 \mathrm{H}), 6.52(\mathrm{~s}, 1 \mathrm{H}), 4.77-4.48(\mathrm{~m}, 2 \mathrm{H}), 4.17(\mathrm{dd}, \mathrm{J}=13.0,8.1,1 \mathrm{H}), 3.40$ (d, J=6.9, 4H), 3.01 (dd, J=8.9, 5.2, 2H), 2.76 (ddd, $J=17.4,10.3,4.8,4 \mathrm{H}), 1.75-1.48(\mathrm{~m}, 4 \mathrm{H}), 1.33$ (dd, J=14.6, 7.2, 2H), 1.06 (t, J=6.9, 6H). 
${ }^{13} \mathrm{C}$ NMR (101 MHz, DMSO-d6) $\delta=173.81,171.62,170.76,162.13,157.72,153.02,148.33,138.15,137.53,132.12,129.84,129.70$, $128.47,126.79,126.70,118.80,115.85,110.66,109.14,108.02,96.27,54.15,54.10,52.22,44.81,39.09,38.45,37.90,30.95,27.05$, $22.85,12.75$.

MS: calculated for $\mathrm{C}_{38} \mathrm{H}_{45} \mathrm{~N}_{5} \mathrm{O}_{7}$ is 683.3319, found 684.3408, $[\mathrm{M}+\mathrm{H}]^{+}$.

(Coumarin 466)-ffk:

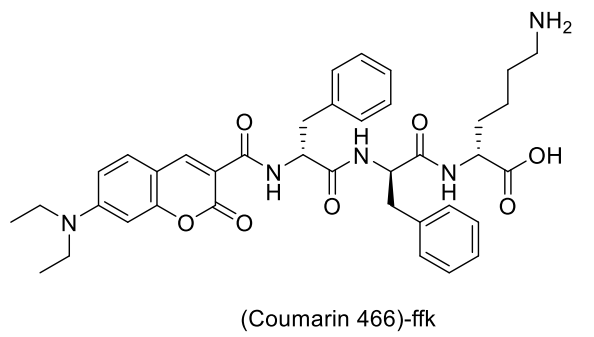

Scheme S5. Chemical structure of (Coumarin 466)-ffk.

compound (Coumarin 466)-ffk was synthesized using the same protocol as compound (Coumarin 466)-FFK, just changed the LFmoc-Amino acids to D-Fmoc-Amino acids. The yield was $81.6 \%$.

${ }^{1} \mathrm{H}$ NMR $(400 \mathrm{MHz}$, DMSO-d6) $\delta=8.80(\mathrm{~d}, \mathrm{~J}=7.9,1 \mathrm{H}), 8.51(\mathrm{~s}, 1 \mathrm{H}), 8.35(\mathrm{~d}, \mathrm{~J}=8.3,1 \mathrm{H}), 8.27(\mathrm{~d}, \mathrm{~J}=7.8,1 \mathrm{H}), 7.59(\mathrm{~d}, \mathrm{~J}=9.1,1 \mathrm{H}), 7.29$ $-7.00(\mathrm{~m}, 10 \mathrm{H}), 6.73(\mathrm{dd}, \mathrm{J}=9.1,2.2,1 \mathrm{H}), 6.52(\mathrm{~d}, \mathrm{~J}=1.9,1 \mathrm{H}), 4.73-4.47(\mathrm{~m}, 2 \mathrm{H}), 4.22-4.11(\mathrm{~m}, 1 \mathrm{H}), 3.46-3.39(\mathrm{~m}, 4 \mathrm{H}), 3.09-$ $2.93(\mathrm{~m}, 2 \mathrm{H}), 2.81-2.66(\mathrm{~m}, 4 \mathrm{H}), 1.79-1.46(\mathrm{~m}, 4 \mathrm{H}), 1.37-1.26(\mathrm{~m}, 2 \mathrm{H}), 1.06(\mathrm{t}, \mathrm{J}=7.0,6 \mathrm{H})$.

${ }^{13} \mathrm{C}$ NMR $(101 \mathrm{MHz}$, DMSO-d6) $\delta=173.81,171.62,170.76,162.12,161.99,157.73,153.04,148.34,138.15,137.52,132.14,129.84$, 129.69, 128.48, 128.46, 126.79, 126.71, 110.68, 109.14, 108.03, 96.28, 54.13, 54.08, 52.19, 44.81, 39.10, 38.45, 37.89, 30.95, 27.04, 22.84, 12.76 .

MS: calculated for $\mathrm{C}_{38} \mathrm{H}_{45} \mathrm{~N}_{5} \mathrm{O}_{7}$ is 683.3319, found 684.3372, $[\mathrm{M}+\mathrm{H}]^{+}$.

(Coumarin 466)-FFK(Boc)-ethylene glycol:

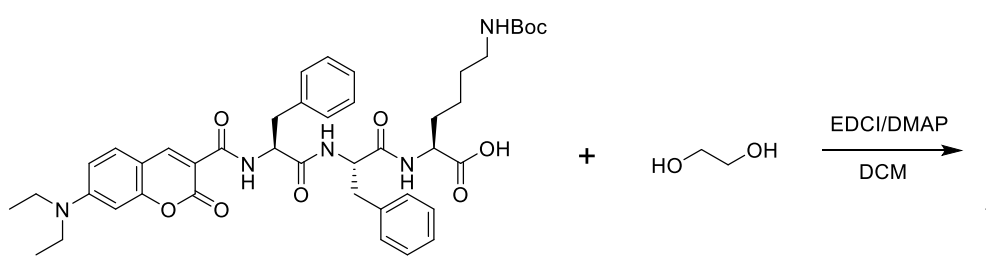

(Coumarin 466)-FFK (Boc)

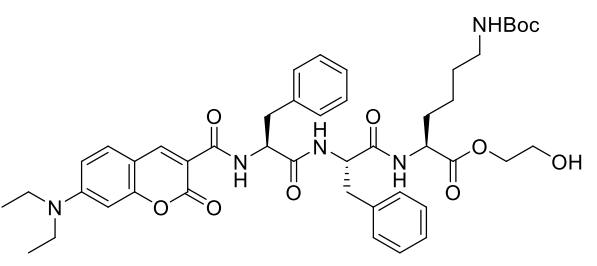

(Coumarin 466)-FFK(Boc)-ethylene glycol

Scheme S6. Synthesis of compound (Coumarin 466)-FFK(Boc)-ethylene glycol.

Compound (Coumarin 466)-FFK(Boc) (100.0 mg, $0.13 \mathrm{mmol})$, EDCl (26.8 mg, $0.14 \mathrm{mmol})$ and DMAP (1.2 mg, $0.01 \mathrm{mmol})$ were added into a $25 \mathrm{~mL}$ round-bottom flask and dissolved by $5 \mathrm{~mL}$ dry DCM, then added ethylene glycol (79.3 mg, $1.3 \mathrm{mmol}$ ) which was dissolved in $2 \mathrm{~mL}$ dry DCM. Stirring at room temperature for $12 \mathrm{~h}$. The target compound was purified by silica column chromatography (Hex : EtOAc $=1: 1)$. The yield was $73.8 \%$.

${ }^{1} \mathrm{H}$ NMR $\left(400 \mathrm{MHz}_{\mathrm{CDCl}}\right) \mathrm{C}=9.25(\mathrm{dd}, \mathrm{J}=66.6,4.4,1 \mathrm{H}), 8.18(\mathrm{~d}, \mathrm{~J}=91.4,1 \mathrm{H}), 7.41-6.73(\mathrm{~m}, 10 \mathrm{H}), 6.63(\mathrm{dd}, \mathrm{J}=11.2,7.7,2 \mathrm{H}), 6.49$ $-6.34(m, 1 H), 4.60-4.30(m, 3 H), 4.11(d d, J=21.5,8.5,2 H), 3.78-3.60(m, 2 H), 3.41(d d, J=6.8,3.7,4 H), 3.19-2.85(m, 6 H)$, $1.72(\mathrm{ddd}, \mathrm{J}=23.1,13.9,7.1,2 \mathrm{H}), 1.37(\mathrm{~d}, \mathrm{~J}=29.9,11 \mathrm{H}), 1.28-1.06(\mathrm{~m}, 8 \mathrm{H})$. 
MS: calculated for $\mathrm{C}_{45} \mathrm{H}_{57} \mathrm{~N}_{5} \mathrm{O}_{10}$ is 827.4105, found 850.3902, $[\mathrm{M}+\mathrm{Na}]^{+}$.

(Coumarin 466)-ffk(Boc)-ethylene glycol:

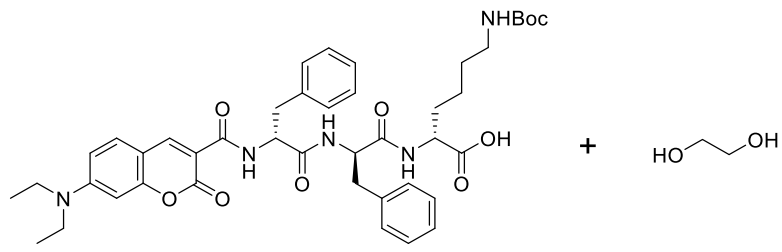

(Coumarin 466)-ffk(Boc)

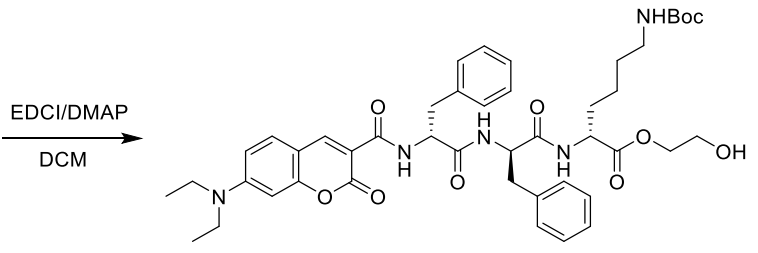

(Coumarin 466)-ffk(Boc)-ethylene glycol

Scheme S7. Synthesis of compound (Coumarin 466)-ffk(Boc)-ethylene glycol.

Compound (Coumarin 466)-ffk(Boc)-ethylene glycol was synthesized using the same method as compound (Coumarin 466)FFK(Boc)-ethylene glycol. The yield was $78.6 \%$.

${ }^{1} \mathrm{H}$ NMR $\left(400 \mathrm{MHz}, \mathrm{CDCl}_{3}\right) \delta=9.37-9.09(\mathrm{~m}, 1 \mathrm{H}), 8.33-8.02(\mathrm{~m}, 1 \mathrm{H}), 7.39-6.88(\mathrm{~m}, 10 \mathrm{H}), 6.69-6.53(\mathrm{~m}, 2 \mathrm{H}), 6.43(\mathrm{dt}, J=14.3$, 7.2, $1 \mathrm{H}), 4.60-4.34(\mathrm{~m}, 3 \mathrm{H}), 4.22-4.04(\mathrm{~m}, 2 \mathrm{H}), 3.72(\mathrm{t}, \mathrm{J}=4.5,2 \mathrm{H}), 3.50-3.35(\mathrm{~m}, 4 \mathrm{H}), 3.16-2.91(\mathrm{~m}, 6 \mathrm{H}), 1.80-1.61(\mathrm{~m}, 2 \mathrm{H})$, $1.40-1.28(\mathrm{~m}, 11 \mathrm{H}), 1.24-1.11(\mathrm{~m}, 8 \mathrm{H})$.

MS: calculated for $\mathrm{C}_{45} \mathrm{H}_{57} \mathrm{~N}_{5} \mathrm{O}_{10}$ is 827.4105 , found $850.3948,[\mathrm{M}+\mathrm{Na}]^{+}$.

\section{(Coumarin 466)-FFK(Boc)-ethylene glycol-Cbl:}

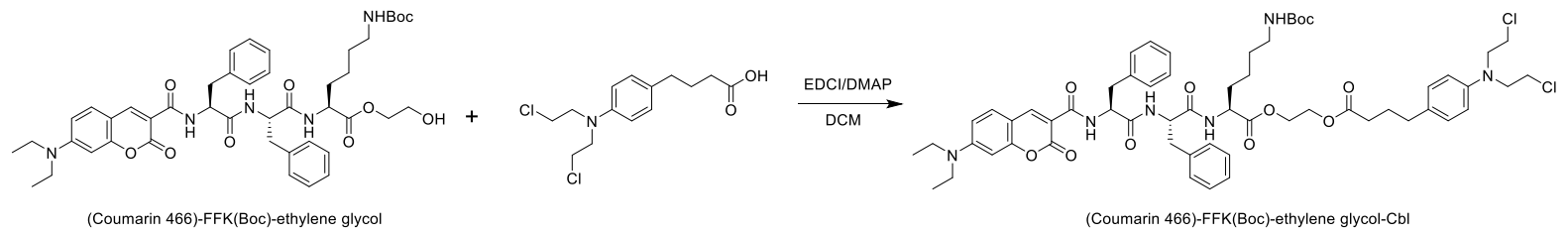

Scheme S8. Synthesis of compound (Coumarin 466)-FFK(Boc)-ethylene glycol-Cbl.

(Coumarin 466)-FFK(Boc)-ethylene glycol $(70.0 \mathrm{mg}, 0.088 \mathrm{mmol})$, EDCl (23.0 mg, $0.12 \mathrm{mmol})$ and DMAP (1.2 mg, $0.01 \mathrm{mmol})$ were added into a $25 \mathrm{~mL}$ round-bottom flask and dissolved by $10 \mathrm{~mL}$ dry DCM, then added chlorambucil (32.9 mg, $0.11 \mathrm{mmol})$ which was dissolved in $2 \mathrm{~mL}$ dry DCM. Stirring at room temperature for $12 \mathrm{~h}$. The target compound was purified by silica column chromatography (Hex : EtOAc $=3: 1)$. The yield was $78.8 \%$.

1H NMR $\left(400 \mathrm{MHz}, \mathrm{CDCl}_{3}\right) \delta=9.13(\mathrm{dd}, \mathrm{J}=11.0,5.3,1 \mathrm{H}), 8.28(\mathrm{~d}, \mathrm{~J}=17.9,1 \mathrm{H}), 7.37-6.92(\mathrm{~m}, 10 \mathrm{H}), 6.84$ (ddd, J=23.0, 15.9, 7.5, 3H), $6.68(\mathrm{~d}, \mathrm{~J}=7.3,1 \mathrm{H}), 6.63-6.51(\mathrm{~m}, 3 \mathrm{H}), 6.43(\mathrm{dd}, \mathrm{J}=9.0,6.2,1 \mathrm{H}), 4.61-4.40(\mathrm{~m}, 3 \mathrm{H}), 4.30-4.15(\mathrm{~m}, 4 \mathrm{H}), 3.64-3.48(\mathrm{~m}, 8 \mathrm{H})$, $3.46-3.33(\mathrm{~m}, 4 \mathrm{H}), 3.18-2.88(\mathrm{~m}, 6 \mathrm{H}), 2.48(\mathrm{td}, \mathrm{J}=7.5,4.6,2 \mathrm{H}), 2.26(\mathrm{dt}, \mathrm{J}=15.9,5.4,2 \mathrm{H}), 1.85-1.56(\mathrm{~m}, 4 \mathrm{H}), 1.38-1.30(\mathrm{~m}$, $11 \mathrm{H}), 1.23-1.12(\mathrm{~m}, 8 \mathrm{H})$.

MS: calculated for $\mathrm{C}_{59} \mathrm{H}_{74} \mathrm{Cl}_{2} \mathrm{~N}_{6} \mathrm{O}_{11}$ is 1112.4793 , found $1135.4666,[\mathrm{M}+\mathrm{Na}]^{+}$.

\section{(Coumarin 466)-ffk(Boc)-ethylene glycol-Cbl:}

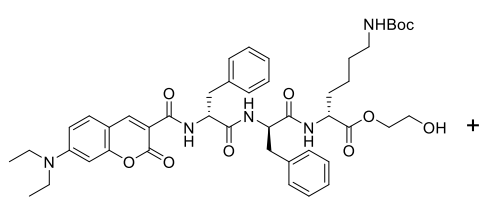

(Coumarin 466)-fik(Boc)-ethylene glycol

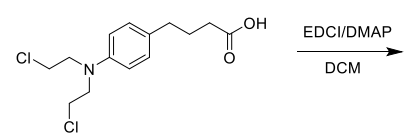

Cl

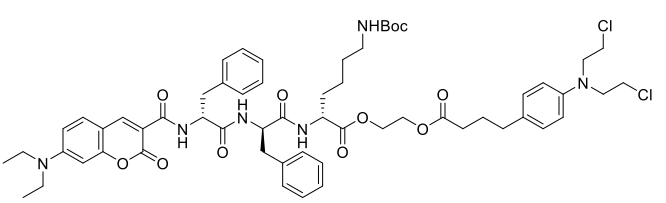

(Coumarin 466)-fk(Boc)-ethylene glycol-Cbl 
Scheme S9. Synthesis of compound (Coumarin 466)-ffk(Boc)-ethylene glycol-Cbl.

(Coumarin 466)-ffk(Boc)-ethylene glycol-Cbl was synthesized using the same method as compound (Coumarin 466)-FFK(Boc)ethylene glycol-Cbl. The yield was $77.9 \%$.

${ }^{1} \mathrm{H}$ NMR $\left(400 \mathrm{MHz}, \mathrm{CDCl}_{3}\right) \delta=9.13(\mathrm{dd}, \mathrm{J}=10.9,5.2,1 \mathrm{H}), 8.28(\mathrm{~d}, \mathrm{~J}=17.5,1 \mathrm{H}), 7.38-6.97(\mathrm{~m}, 10 \mathrm{H}), 6.84$ (ddd, J=20.4, 16.1, 7.6, 3H), $6.68(\mathrm{~d}, \mathrm{~J}=7.3,1 \mathrm{H}), 6.66-6.49(\mathrm{~m}, 3 \mathrm{H}), 6.44(\mathrm{t}, \mathrm{J}=2.8,1 \mathrm{H}), 4.64-4.39(\mathrm{~m}, 3 \mathrm{H}), 4.31-4.12(\mathrm{~m}, 4 \mathrm{H}), 3.71-3.47(\mathrm{~m}, 8 \mathrm{H}), 3.48$ $-3.30(\mathrm{~m}, 4 \mathrm{H}), 3.26-2.87(\mathrm{~m}, 6 \mathrm{H}), 2.54-2.40(\mathrm{~m}, 2 \mathrm{H}), 2.29(\mathrm{t}, \mathrm{J}=7.5,2 \mathrm{H}), 1.77-1.53(\mathrm{~m}, 4 \mathrm{H}), 1.39-1.30(\mathrm{~m}, 11 \mathrm{H}), 1.28-1.11$ $(\mathrm{m}, 8 \mathrm{H})$.

MS: calculated for $\mathrm{C}_{59} \mathrm{H}_{74} \mathrm{Cl}_{2} \mathrm{~N}_{6} \mathrm{O}_{11}$ is 1112.4793 , found $1135.4665,[\mathrm{M}+\mathrm{Na}]^{+}$.

SJC-1:

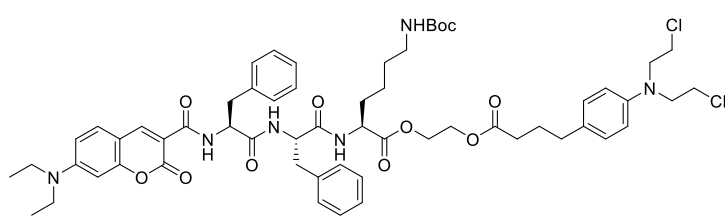

(Coumarin 466)-FFK(Boc)-ethylene glycol-Cb

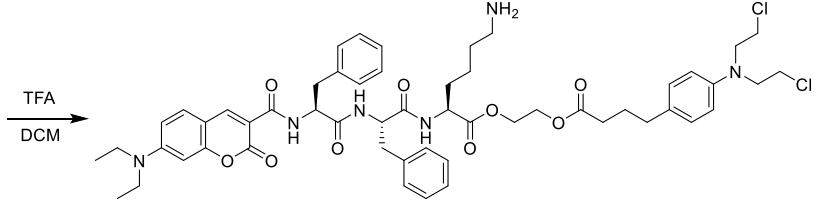

SJC-1

Scheme S10. Synthesis of compound SJC-1.

(Coumarin 466)-FFK(Boc)-ethylene glycol-Cbl $(50.0 \mathrm{mg}, 0.045 \mathrm{mmol})$ was dissolved in $10 \mathrm{~mL}$ dried DCM and cooled down to $0{ }^{\circ} \mathrm{C}$, then $2 \mathrm{~mL}$ TFA was slowly dropped into the solution. Stirring at $0{ }^{\circ} \mathrm{C}$ for $5 \mathrm{~h}$, and the target compound was purified by HPLC, the yield was $85.6 \%$.

${ }^{1} \mathrm{H}$ NMR $(400 \mathrm{MHz}$, DMSO-d6) $\delta=8.88(\mathrm{dd}, \mathrm{J}=10.5,7.8,1 \mathrm{H}), 8.58(\mathrm{~d}, \mathrm{~J}=2.9,1 \mathrm{H}), 8.47-8.39(\mathrm{~m}, 1 \mathrm{H}), 7.68-7.61(\mathrm{~m}, 1 \mathrm{H}), 7.31-$ $7.09(\mathrm{~m}, 10 \mathrm{H}), 7.00(\mathrm{dt}, \mathrm{J}=8.3,7.4,2 \mathrm{H}), 6.80(\mathrm{dd}, \mathrm{J}=9.1,2.2,1 \mathrm{H}), 6.69-6.57(\mathrm{~m}, 3 \mathrm{H}), 4.77-4.50(\mathrm{~m}, 2 \mathrm{H}), 4.32-4.16(\mathrm{~m}, 5 \mathrm{H}), 3.68$ (t, J=6.7, 8H), $3.48(\mathrm{dd}, \mathrm{J}=14.0,6.9,4 \mathrm{H}), 3.07-2.68(\mathrm{~m}, 6 \mathrm{H}), 2.47-2.38(\mathrm{~m}, 2 \mathrm{H}), 2.32-2.22(\mathrm{~m}, 2 \mathrm{H}), 1.80-1.25(\mathrm{~m}, 10 \mathrm{H}), 1.14(\mathrm{t}$, $J=7.0,6 \mathrm{H})$.

${ }^{13} \mathrm{C}$ NMR $(101 \mathrm{MHz}$, DMSO- $d 6) \delta=173.12,172.21,171.45,170.67,162.29,161.99,157.75,153.05,148.35,144.95,137.95,137.40$, 132.12, 129.90, 129.79, 129.76, 129.64, 128.52, 126.76, 112.37, 112.35, 110.68, 109.16, 108.02, 96.30, 63.02, 62.41, 62.27, 54.37, $54.24,52.65,52.09,44.82,41.61,33.81,33.68,33.23,30.74,26.93,25.78,24.93,22.49,21.07,12.76$.

MS: calculated for $\mathrm{C}_{54} \mathrm{H}_{66} \mathrm{Cl}_{2} \mathrm{~N}_{6} \mathrm{O}_{9}$ is 1012.4268 , found 1013.4240, $[\mathrm{M}+\mathrm{H}]^{+}$.

\section{SJC-2:}

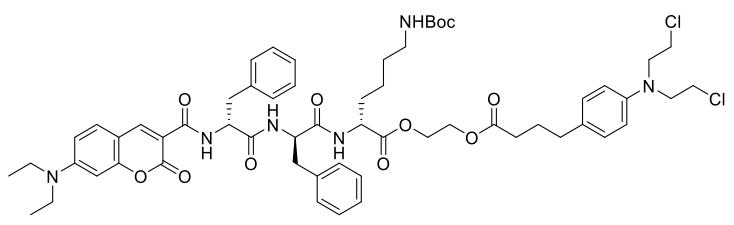

(Coumarin 466)-ffk(Boc)-ethylene glycol-Cb

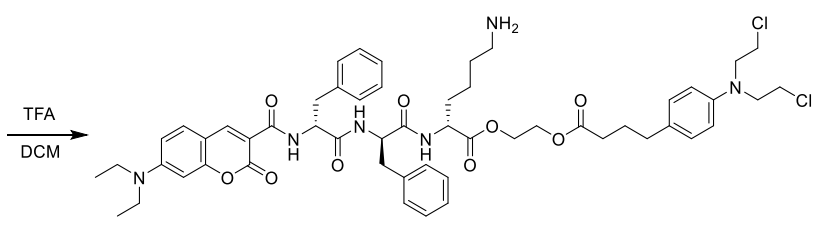

SJC-2

Scheme S11. Synthesis of compound SJC-2. 
(Coumarin 466)-ffk(Boc)-ethylene glycol-Cbl $(50.0 \mathrm{mg}, 0.045 \mathrm{mmol})$ was dissolved in $10 \mathrm{~mL}$ dried $\mathrm{DCM}$ and cooled down to $0{ }^{\circ} \mathrm{C}$, then $2 \mathrm{~mL}$ TFA was slowly dropped into the solution. Stirring at $0{ }^{\circ} \mathrm{C}$ for $5 \mathrm{~h}$, and the target compound was purified by HPLC, the yield was $82.8 \%$.

${ }^{1} \mathrm{H}$ NMR $(400 \mathrm{MHz}$, DMSO-d6) $\delta=8.91-8.88(\mathrm{~m}, 1 \mathrm{H}), 8.61-8.53(\mathrm{~m}, 1 \mathrm{H}), 8.44(\mathrm{~s}, 1 \mathrm{H}), 7.79-7.61(\mathrm{~m}, 3 \mathrm{H}), 7.39-6.91(\mathrm{~m}, 10 \mathrm{H})$, $6.81(\mathrm{~s}, 1 \mathrm{H}), 6.71-6.49(\mathrm{~m}, 2 \mathrm{H}), 4.80-4.59(\mathrm{~m}, 2 \mathrm{H}), 4.40-4.15(\mathrm{~m}, 5 \mathrm{H}), 3.80-3.65(\mathrm{~m}, 8 \mathrm{H}), 3.15-2.93(\mathrm{~m}, 4 \mathrm{H}), 2.89-2.66(\mathrm{~m}$, $6 \mathrm{H}), 2.46-2.38(\mathrm{~m}, 2 \mathrm{H}), 2.31-2.20(\mathrm{~m}, 2 \mathrm{H}), 1.84-1.35(\mathrm{~m}, 10 \mathrm{H}), 1.12(\mathrm{t}, \mathrm{J}=7.0,6 \mathrm{H})$.

${ }^{13} \mathrm{C}$ NMR $(101 \mathrm{MHz}$, DMSO-d6) $\delta=173.12,172.36,171.45,170.50,162.00,157.70,157.07,152.88,148.36,144.95,137.35,132.13$, $129.77,129.64,128.50,126.81,112.34,110.69,108.02,63.03,62.20,54.19,52.64,52.15,47.98,44.82,41.61,33.81,33.24,26.93$ $25.78,24.93,22.50,12.77$.

MS: calculated for $\mathrm{C}_{54} \mathrm{H}_{66} \mathrm{Cl}_{2} \mathrm{~N}_{6} \mathrm{O}_{9}$ is 1012.4268 , found 1013.4248, $[\mathrm{M}+\mathrm{H}]^{+}$.

\section{(Coumarin 466)-FFK-Ace:}

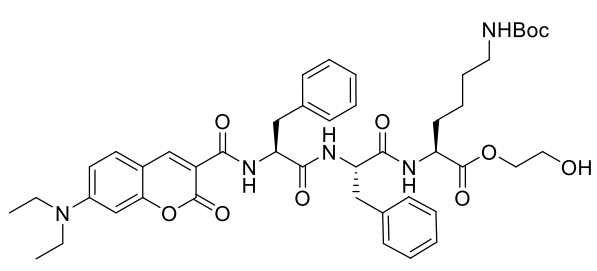

(Coumarin 466)-FFK(Boc)-ethylene glycol

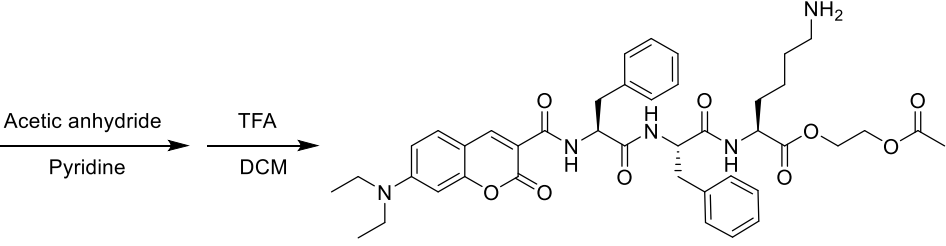

(Coumarin 466)-FFK-Ace

Scheme S12. Synthesis of compound (Coumarin 466)-FFK-Ace.

(Coumarin 466)-FFK(Boc)-ethylene glycol $(79.3 \mathrm{mg}, 0.096 \mathrm{mmol})$ and acetic anhydride $(14.7 \mathrm{mg}, 0.144 \mathrm{mmol})$ were dissolved by 10 $\mathrm{mL}$ of pyridine at $25 \mathrm{~mL}$ round-bottom flask, the mixture was stirred at room temperature overnight. Pyridine was removed under reduced pressure rotor evaporator. The mixture was dissolved in $10 \mathrm{~mL}$ dried $\mathrm{DCM}$, cooling down to $0{ }^{\circ} \mathrm{C}$ in ice bath. $3 \mathrm{~mL}$ of TFA was slowly dropped into the mixture and stirred at $0{ }^{\circ} \mathrm{C}$ for $5 \mathrm{~h}$. The target compound was purified by HPLC, the yield was $79.3 \%$.

${ }^{1} \mathrm{H}$ NMR $(400 \mathrm{MHz}$, DMSO-d6) $\delta 8.92-8.83(\mathrm{~m}, 1 \mathrm{H}), 8.58(\mathrm{~d}, J=3.0 \mathrm{~Hz}, 1 \mathrm{H}), 8.52-8.40(\mathrm{~m}, 2 \mathrm{H}), 7.65(\mathrm{~s}, 1 \mathrm{H}), 7.32-7.12(\mathrm{~m}, 10 \mathrm{H})$, $6.80(\mathrm{~d}, J=9.1 \mathrm{~Hz}, 1 \mathrm{H}), 6.60(\mathrm{dd}, J=4.3,2.3 \mathrm{~Hz}, 1 \mathrm{H}), 4.85-4.51(\mathrm{~m}, 3 \mathrm{H}), 4.32-4.20(\mathrm{~m}, 4 \mathrm{H}), 3.51-3.46(\mathrm{~m}, 4 \mathrm{H}), 3.09-2.99(\mathrm{~m}$, 2H), $2.87-2.71(\mathrm{~m}, 4 \mathrm{H}), 2.00(\mathrm{~d}, J=6.5 \mathrm{~Hz}, 3 \mathrm{H}), 1.72-1.19(\mathrm{~m}, 8 \mathrm{H}), 1.14(\mathrm{t}, J=7.0 \mathrm{~Hz}, 6 \mathrm{H})$.

${ }^{13} \mathrm{C}$ NMR (101 MHz, DMSO- $\left.d 6\right) \delta$ 172.23, 171.45, 170.70, 161.99, 157.75, 153.05, 148.36, 137.94, 137.41, 132.14, 129.84, 129.82, $129.65,128.51,128.46,126.80,126.76,110.69,109.15,108.03,96.31,62.96,62.35,62.26,54.20,52.09,44.81,40.89,38.46,30.75$, 26.90, 22.47, 21.05, 12.77 .

MS: calculated for $\mathrm{C}_{42} \mathrm{H}_{51} \mathrm{~N}_{5} \mathrm{O}_{9}$ is 769.3687 , found $770.3703,[\mathrm{M}+\mathrm{H}]^{+}$.

\section{(Coumarin 466)-ffk-Ace:}

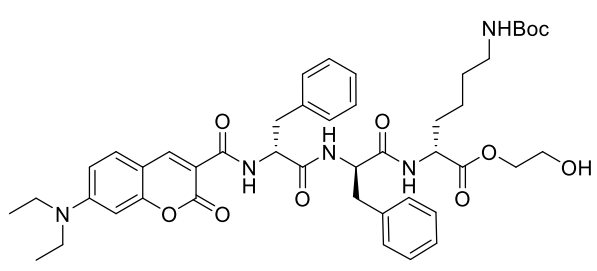

(Coumarin 466)-ffk(Boc)-ethylene glycol

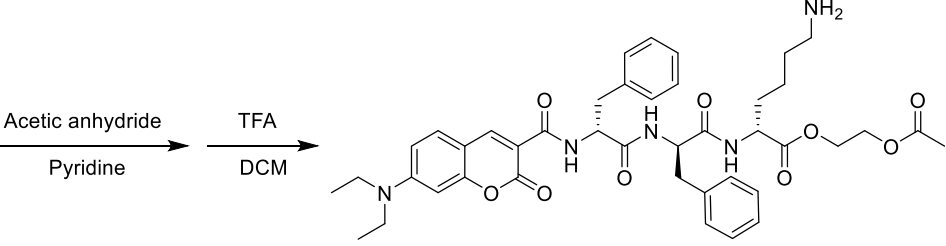

(Coumarin 466)-ffk-Ace 


\section{SUPPORTING INFORMATION}

(Coumarin 466)-ffk-Ace was synthesized according to the same procedure of compound (Coumarin 466)-FFK-Ace, the yield was $82.3 \%$.

${ }^{1} \mathrm{H}$ NMR (400 MHz, DMSO-d6) $\delta 8.90-8.83(\mathrm{~m}, 1 \mathrm{H}), 8.58$ (d, J = 2.8 Hz, 1H), 8.47 (dd, J = 30.1, $\left.7.9 \mathrm{~Hz}, 2 \mathrm{H}\right), 7.67(\mathrm{~s}, 1 \mathrm{H}), 7.30-$ $7.11(\mathrm{~m}, 10 \mathrm{H}), 6.81(\mathrm{~d}, J=9.1 \mathrm{~Hz}, 1 \mathrm{H}), 6.61-6.58(\mathrm{~m}, 1 \mathrm{H}), 4.78-4.54(\mathrm{~m}, 3 \mathrm{H}), 4.32-4.19(\mathrm{~m}, 4 \mathrm{H}), 3.48(\mathrm{q}, J=7.0 \mathrm{~Hz}, 1 \mathrm{H}), 3.10-$ $3.01(\mathrm{~m}, 2 \mathrm{H}), 2.87-2.70(\mathrm{~m}, 4 \mathrm{H}), 1.99(\mathrm{~d}, J=7.4 \mathrm{~Hz}, 3 \mathrm{H}), 1.80-1.22(\mathrm{~m}, 8 \mathrm{H}), 1.14(\mathrm{t}, J=7.0 \mathrm{~Hz}, 6 \mathrm{H})$.

${ }^{13} \mathrm{C}$ NMR (101 MHz, DMSO-d6) $\delta 172.17,171.88,170.80,170.69,162.11,157.74,153.05,148.36,138.13,137.50,132.15,129.84$, $129.65,129.63,128.52,128.46,126.79,126.77,110.69,109.13,108.03,96.29,62.97,62.35,54.07,52.29,46.70,44.81,39.08$, $30.67,26.98,22.68,21.04,12.77$.

MS: calculated for $\mathrm{C}_{42} \mathrm{H}_{51} \mathrm{~N}_{5} \mathrm{O}_{9}$ is 769.3687 , found 770.3701 , [M $\left.+\mathrm{H}\right]^{+}$.
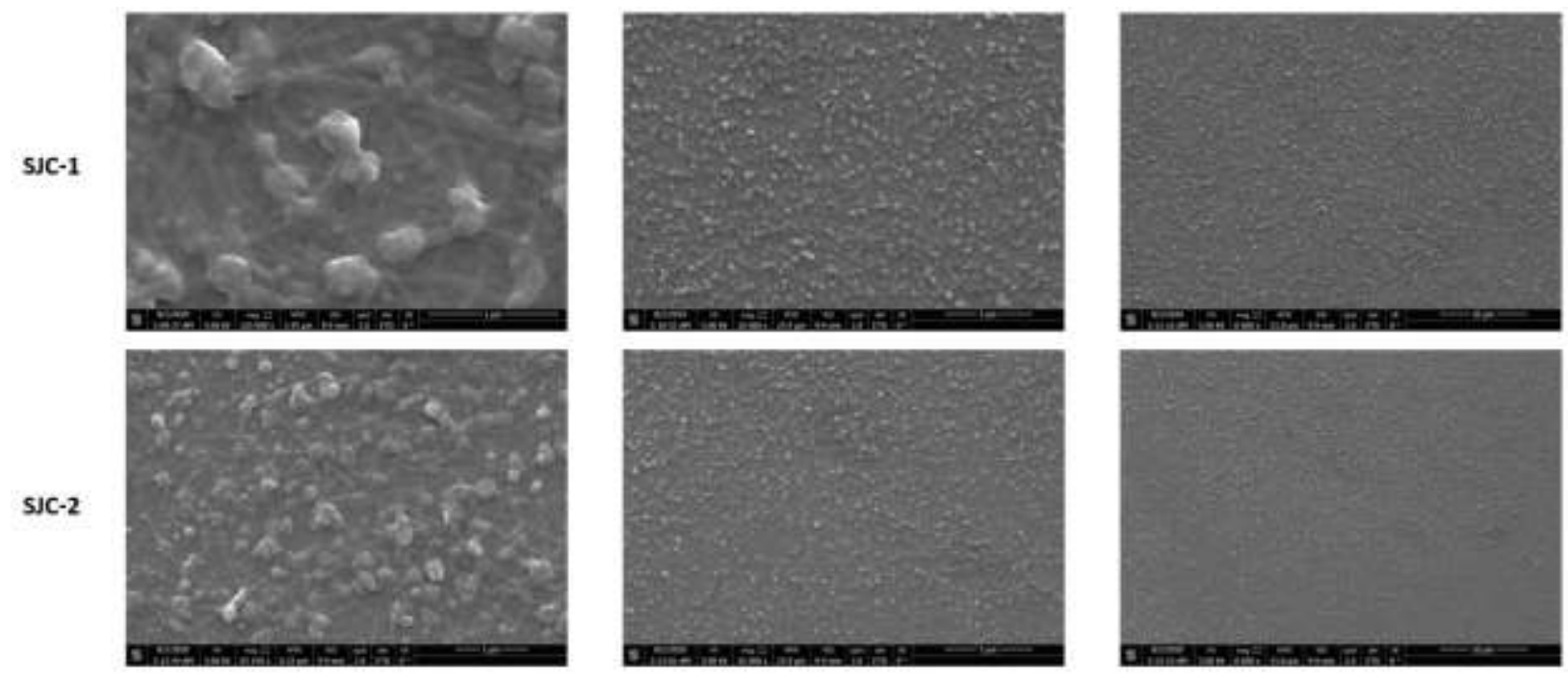

Figure S1. SEM image of compound SJC-1, SJC-2 at $100 \mu \mathrm{M}$.
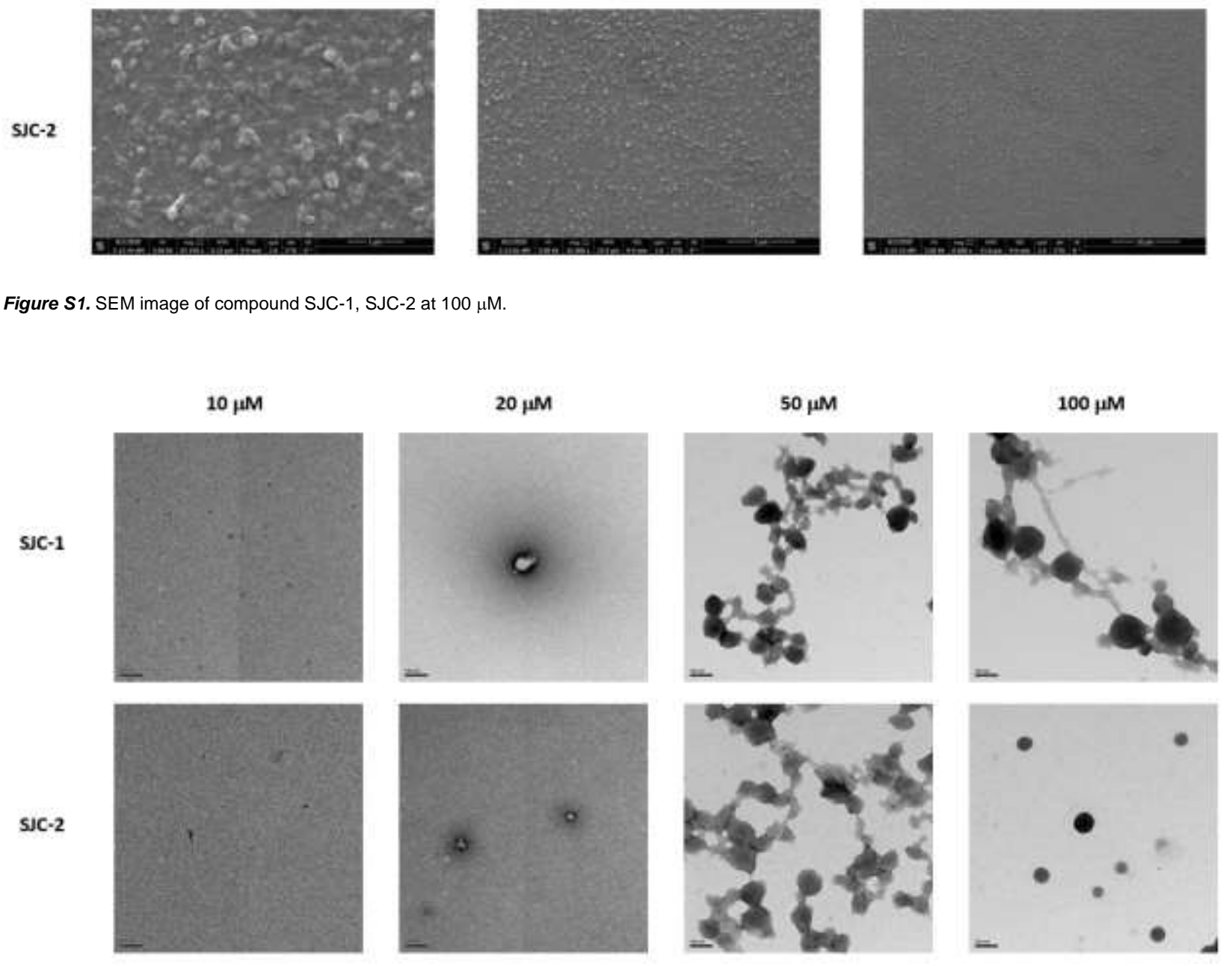

Figure S2. TEM images of compound SJC-1 and SJC-2 in water at various concentrations. Scale basr represent $100 \mathrm{~nm}$. 


\section{CES catalyzed hydrolysis}

In buffer

a
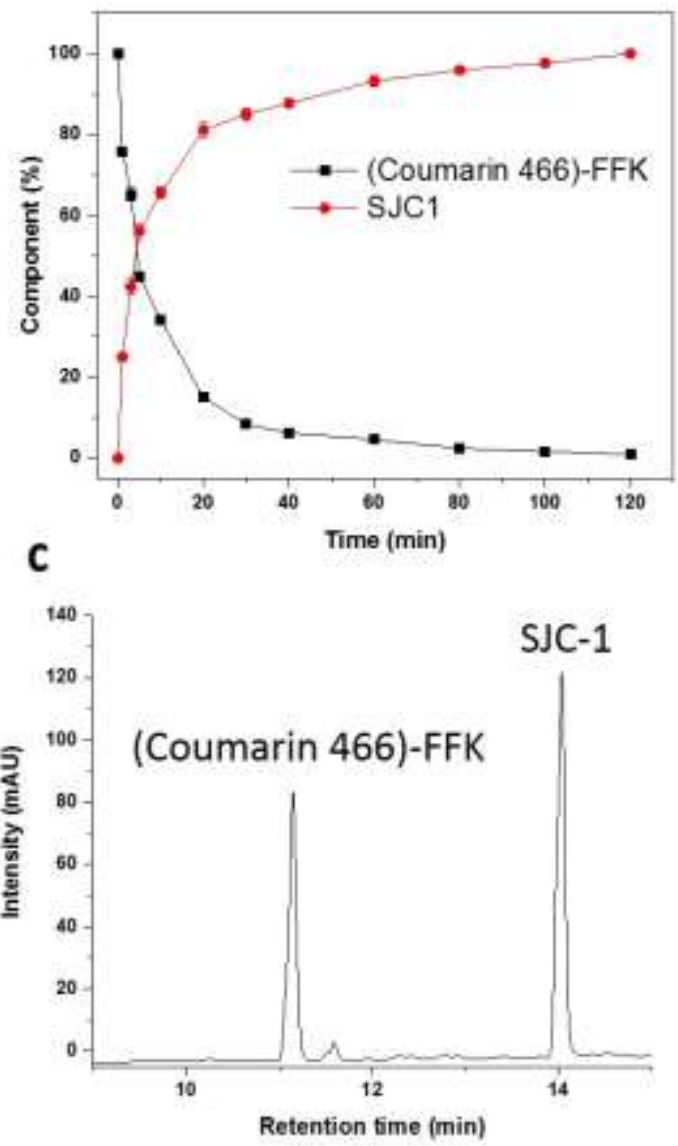

b

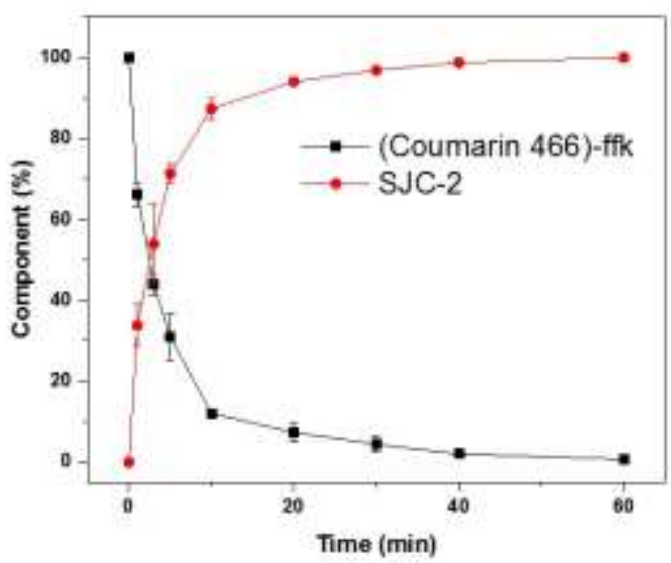

d

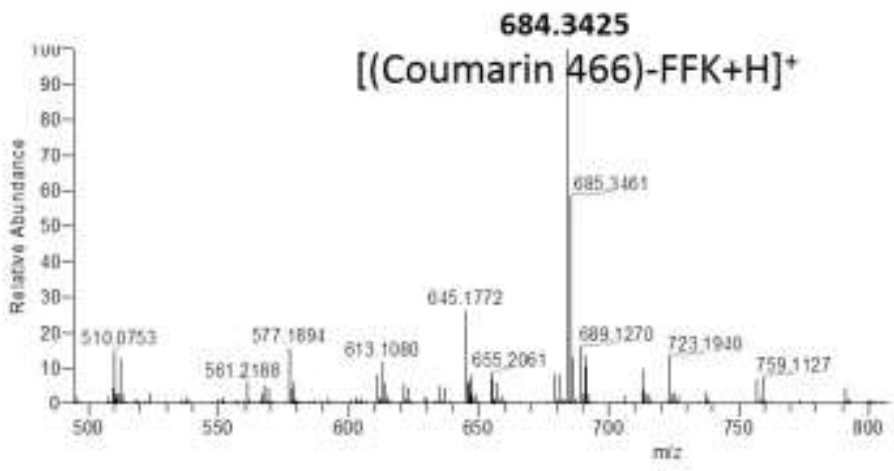

Figure S3. Kinetic profiles of CES catalysed hydrolysis of SJC-1 (a) and SJC-2 (b) in borate buffer at $37^{\circ} \mathrm{C}$; (c) HPLC spectrum of CES catalyzed-hydrolysis of SJC-1 at 3 min. (d) MS spectrum of fraction of peak 3 during the hydrolysis process of SJC-1, confirming it is (Coumarin 466)-FFK. 
Intracellular hydrolysis analysis

a

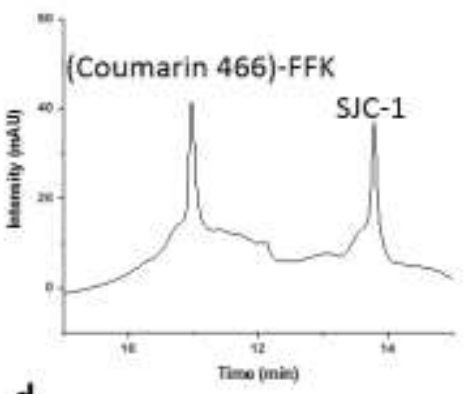

d

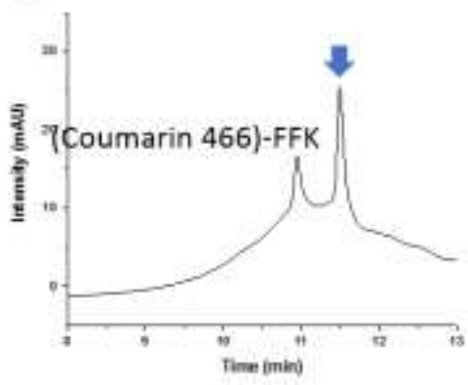

b

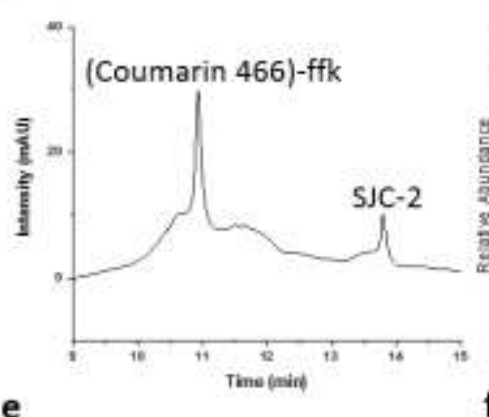

e

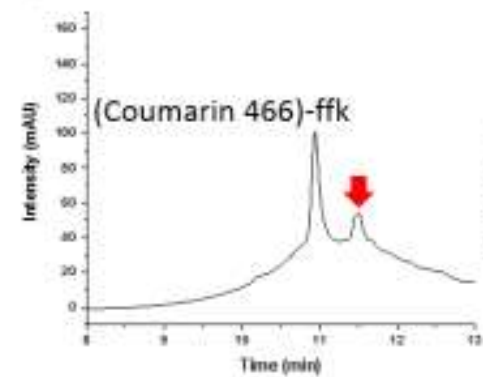

c


Figure S4. HPLC spectra of MCF-7 cell lysate supernatant treated by SJC-1 (a), SJC-2 (b), (Coumarin 466)-FFK-Ace (blue arrow) (d) and (Coumarin 466)-ffk-Ace (red arrow) (e), MS spectra of fraction (Coumarin 466)-FFK (c) and (Coumarin 466)-ffk (f), confirming intra cellular hydrolysis of SJC-1, SJC-2, (Coumarin 466)FFK-Ace, and (Coumarin 466)-ffk-Ace after cellular uptake.

UV-Vis absorption and fluorescence emission spectroscopy

a

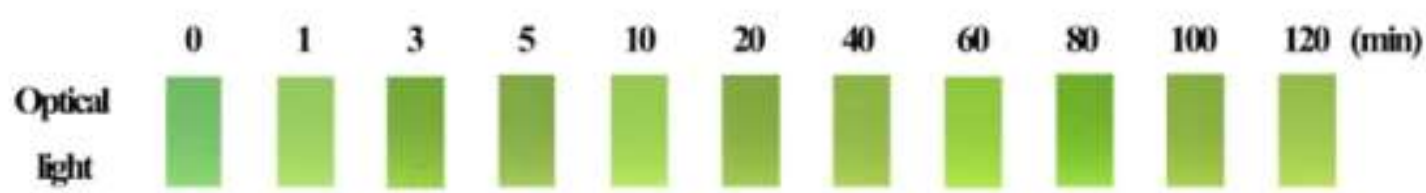

UV Eght

(3650
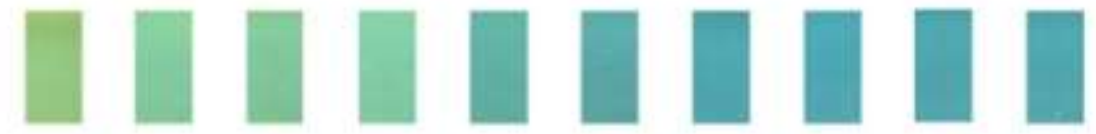

b

C
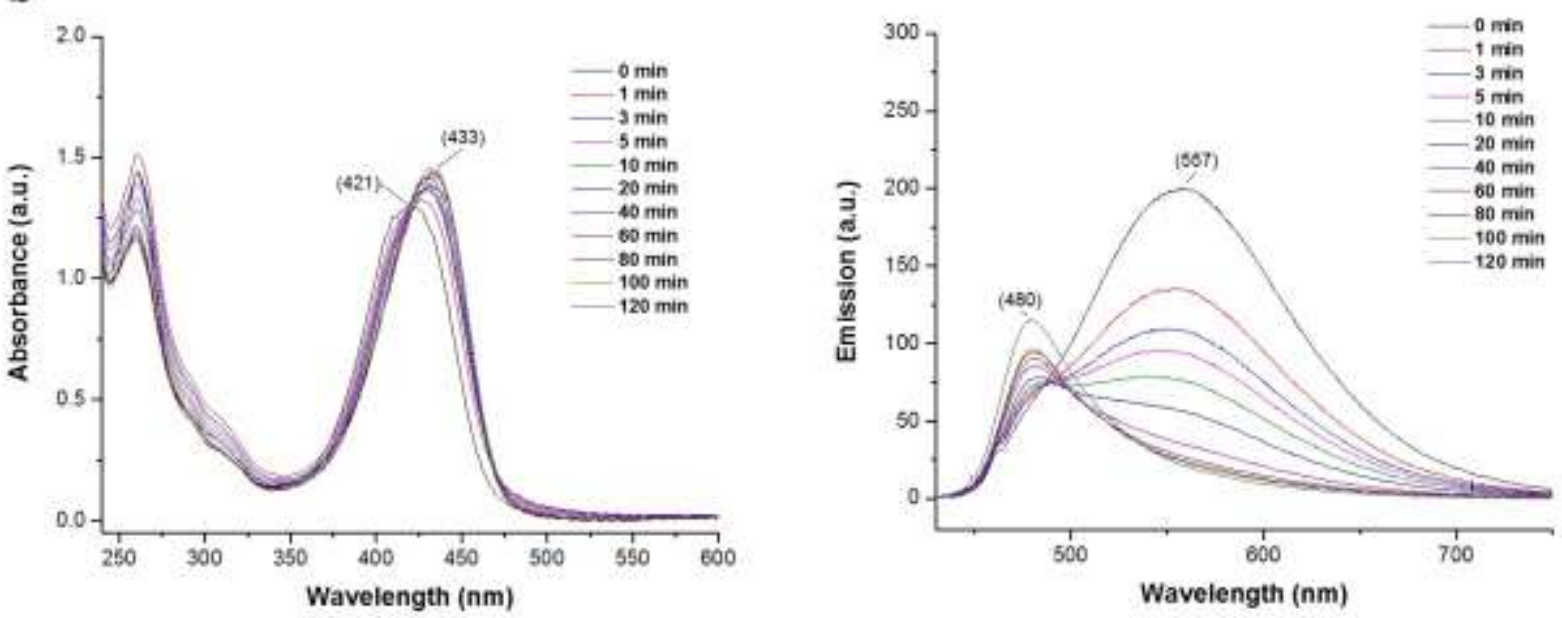
d
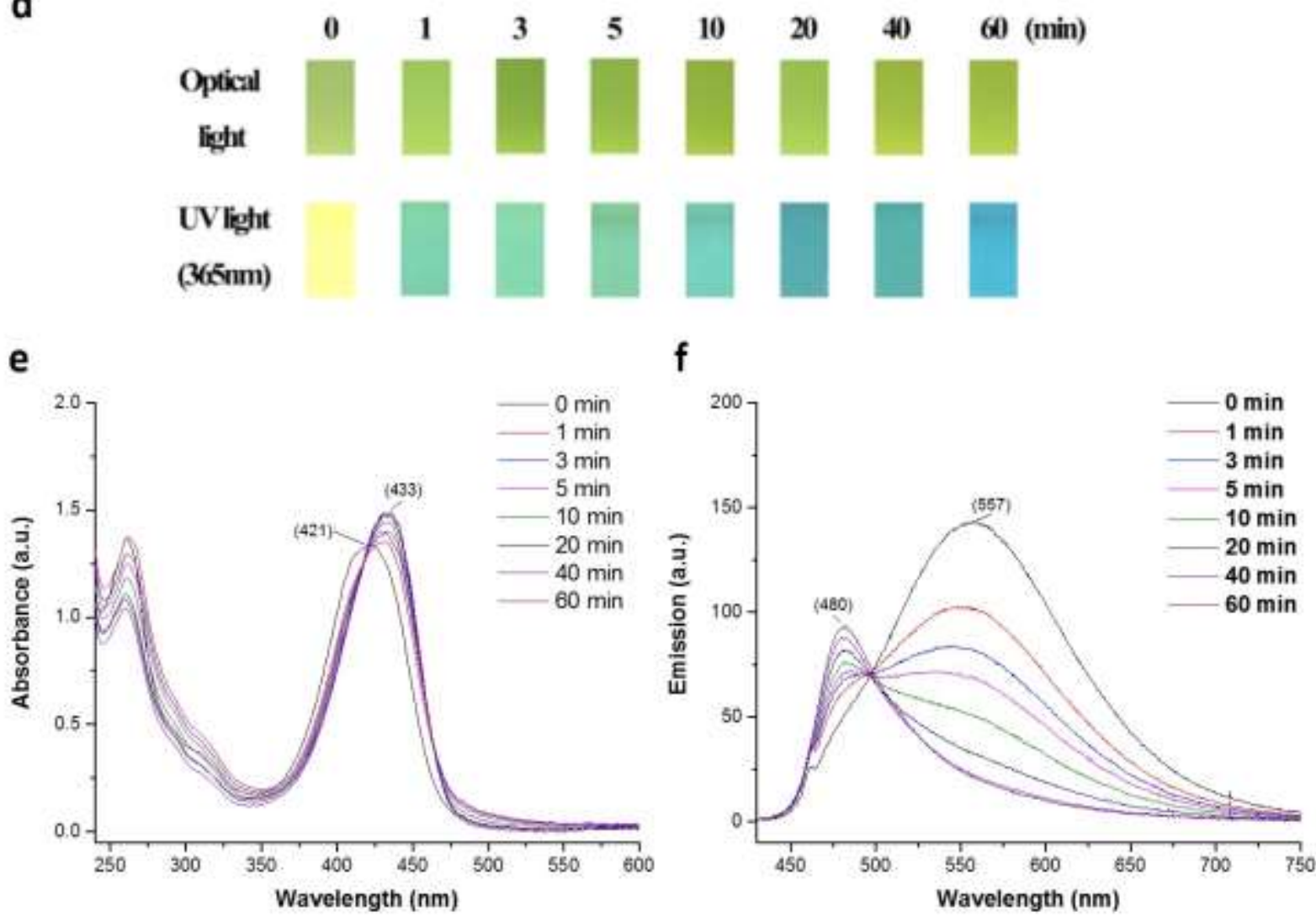

Figure S5. (a) Time-dependent optical images under normal light (upper row) and UV light (bottom row) of SJC-1 (100 $\mu \mathrm{M}$ with $1 \mathrm{u}$ of CES) in borate buffer at 37 ${ }^{\circ} \mathrm{C}$. Time-dependent UV-Vis absorbance (b) and emission spectra (ex. 405nm) (c) of SJC-1 (100 $\mu \mathrm{M}$ with $1 \mathrm{u}$ of CES) in borate buffer; Time-dependent optical images under the normal light (upper row) and uv light (bottom row) of SJC-2 (100 $\mu \mathrm{M}$ with 1u of CES) in borate buffer (d). Time-dependent UV-Vis absorbance (e) and emission spectra (ex. $405 \mathrm{~nm})$ (f) of SJC-2 (100 $\mu \mathrm{M}$ with $1 \mathrm{u}$ of CES) in borate buffer.

\section{Confocal microscopy imaging}

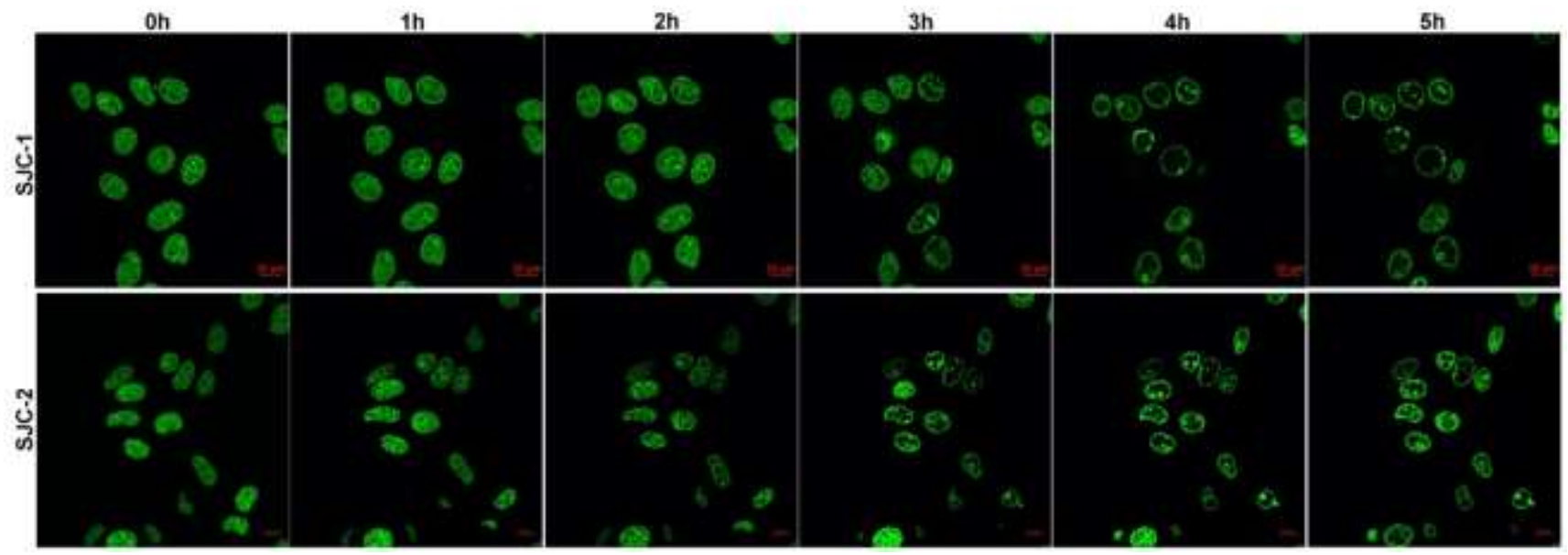

Figure S6. Time-lapse confocal imaging of HeLa-H2B(GFP) cells upton the treatment of SJC-1 and SJC-2 at concentration of $50 \mu \mathrm{M}$ 


\section{Flow cytometry analysis of cell cycle distribution}
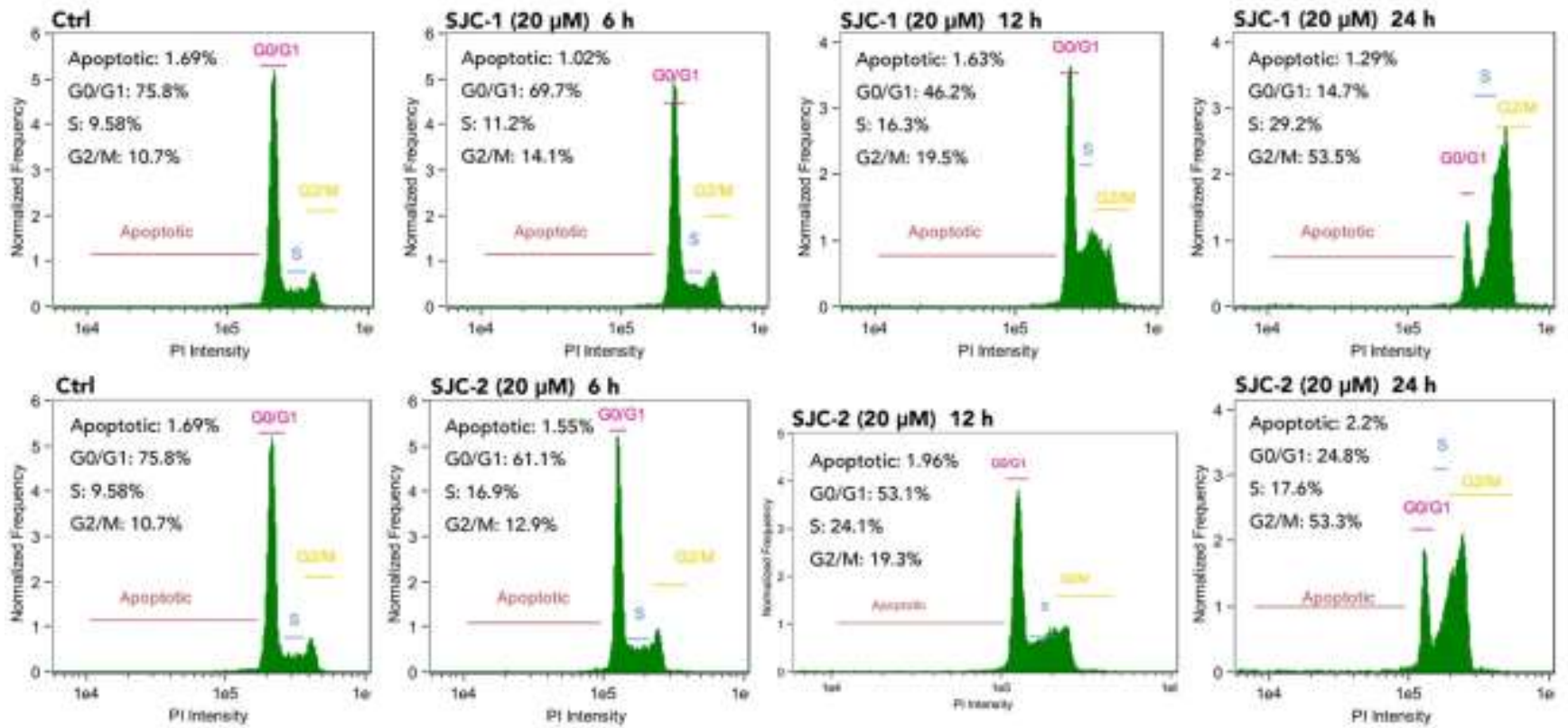

Figure S7. Time-dependent flow cytometry analysis for cell cycle distribution of HeLa cells without any treatment, and upon the treatment of SJC-1 and SJC-2 at concentration of $20 \mu \mathrm{M}$

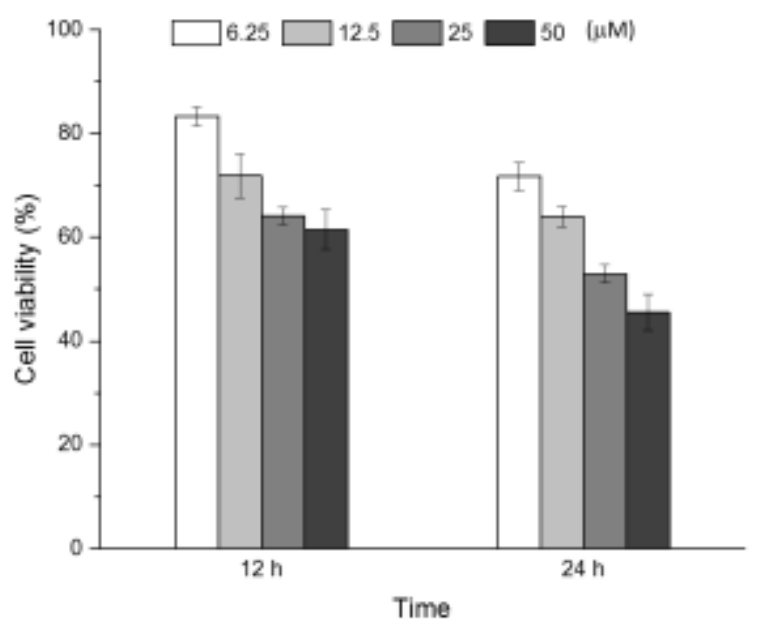

Figure S8. MCF-7 cell viability upon the treatment of cisplatin.
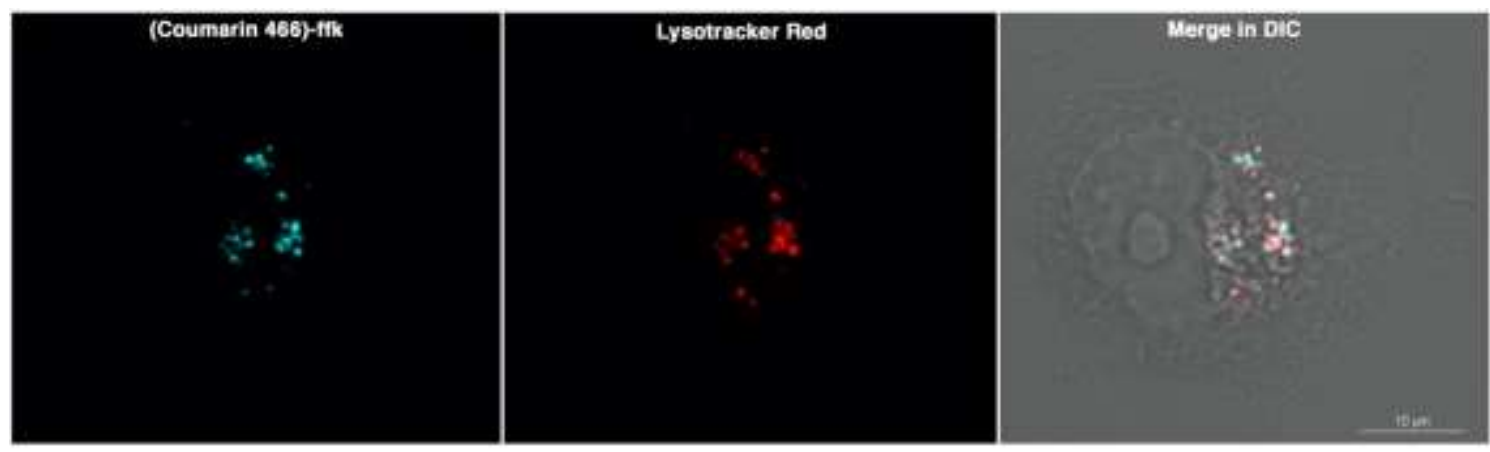

Figure S9. Intracellular localization of (Coumarin 466)-ffk in MCF-7 cells upon the treatment of (Coumarin 466)-ffk co-stained with Lysotracker Red. 


\section{Western blotting}
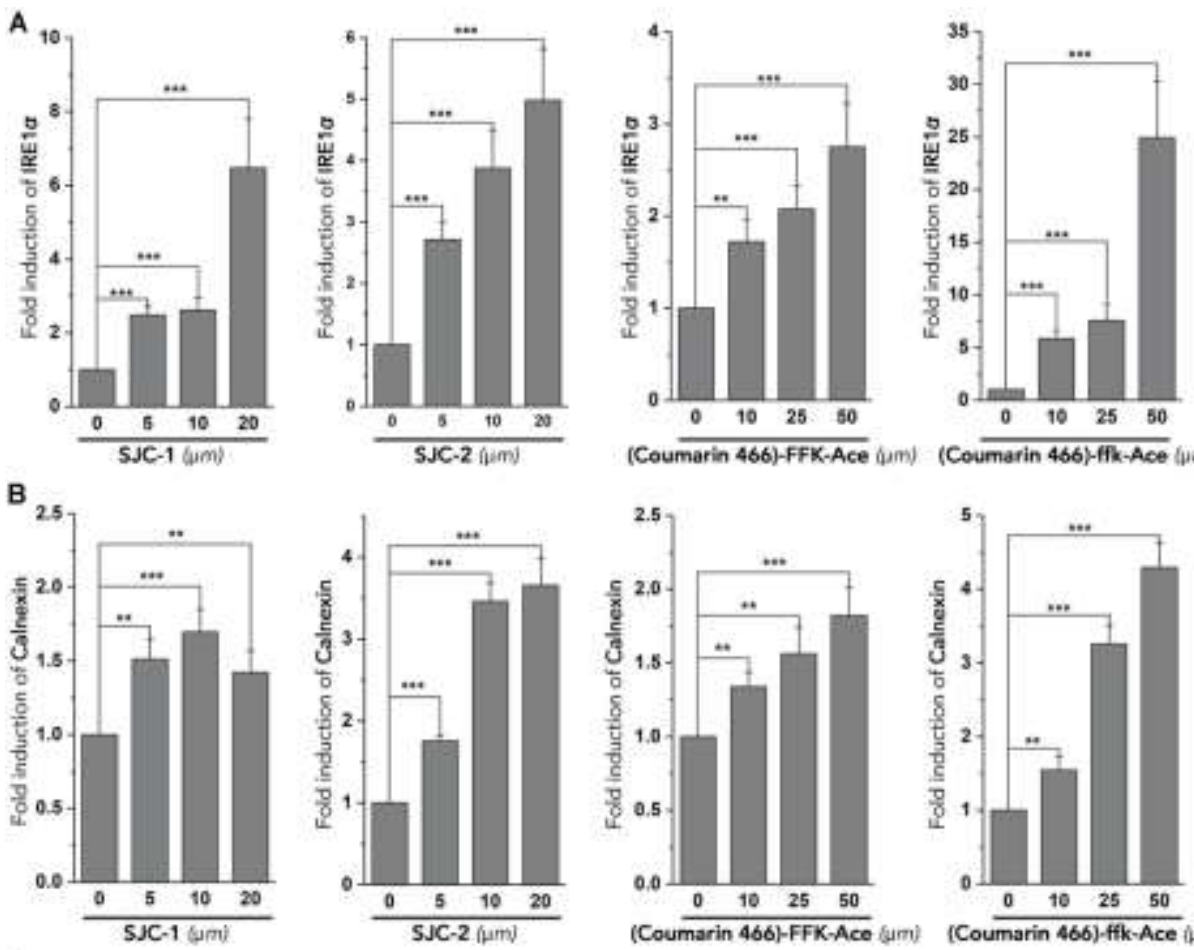

(Coumarin 466)-FFK-Ace (um) (Coumarin 466)-fik-Ace (um)
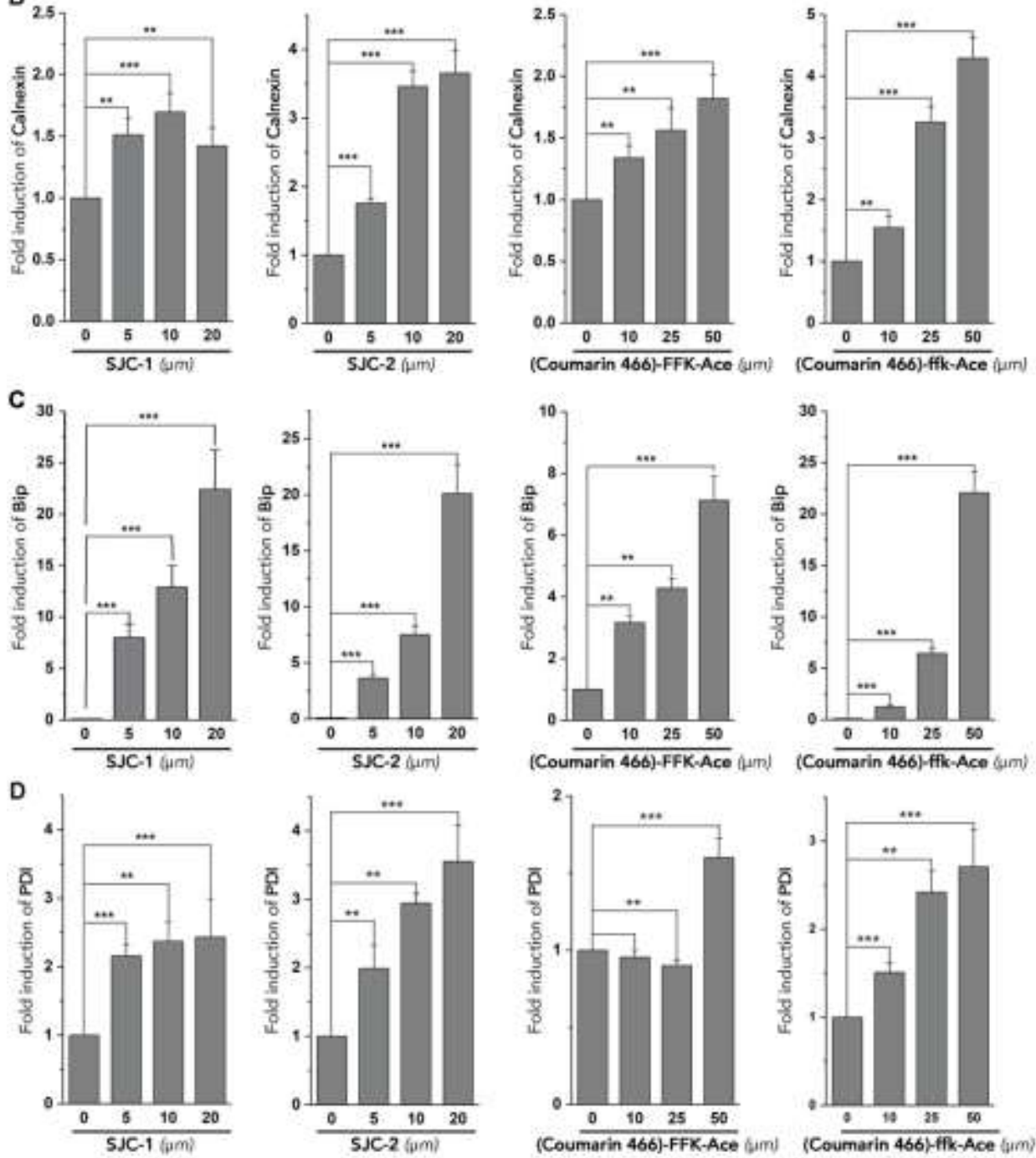

Figure S10. Quantitative analysis of IRE1 $\alpha$ (A), Calnexin (B), Bip (C), and PDI (D) expression in MCF-7 cells upon the treatment of SJC-1, SJC-2, (Coumarin 466)-FFK-Ace, and (Coumarin 466)-ffk-Ace. 
a

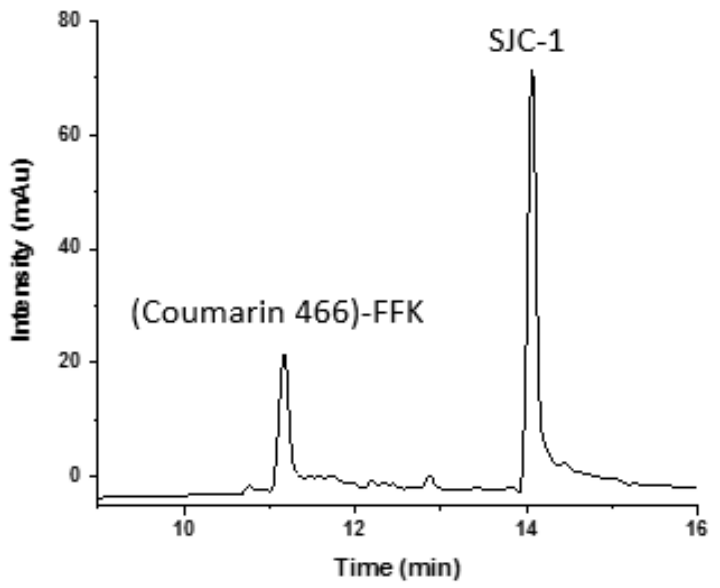

b

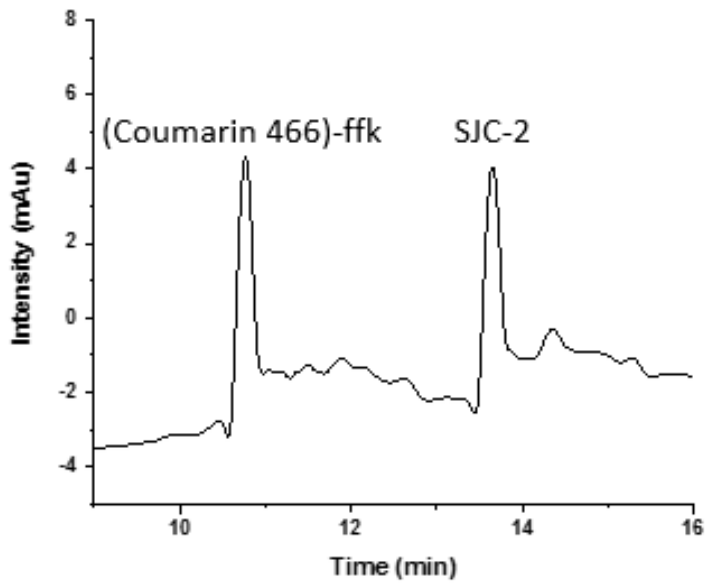

Figure S11. HPLC analysis of CES catalysed hydrolysis of SJC-1 (a) and SJC-2 (b) aggregates in borate buffer at $37^{\circ} \mathrm{C}$ for 2 hours and 1 hour, respectively. 


\section{Chemical structure characterization}

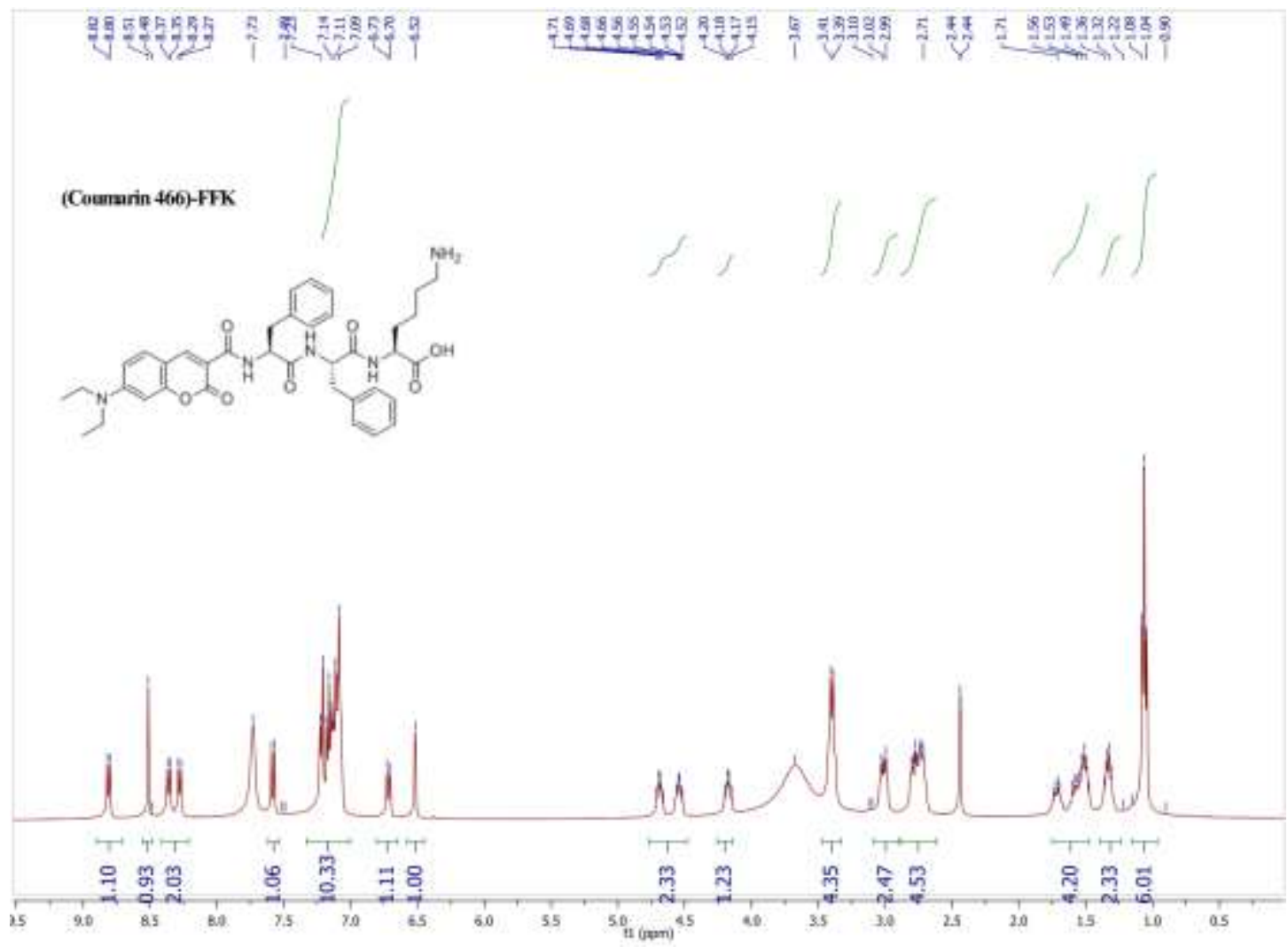

Figure S12. ${ }^{1} \mathrm{H}$ NMR spectrum of (Coumarin 466)-FFK.

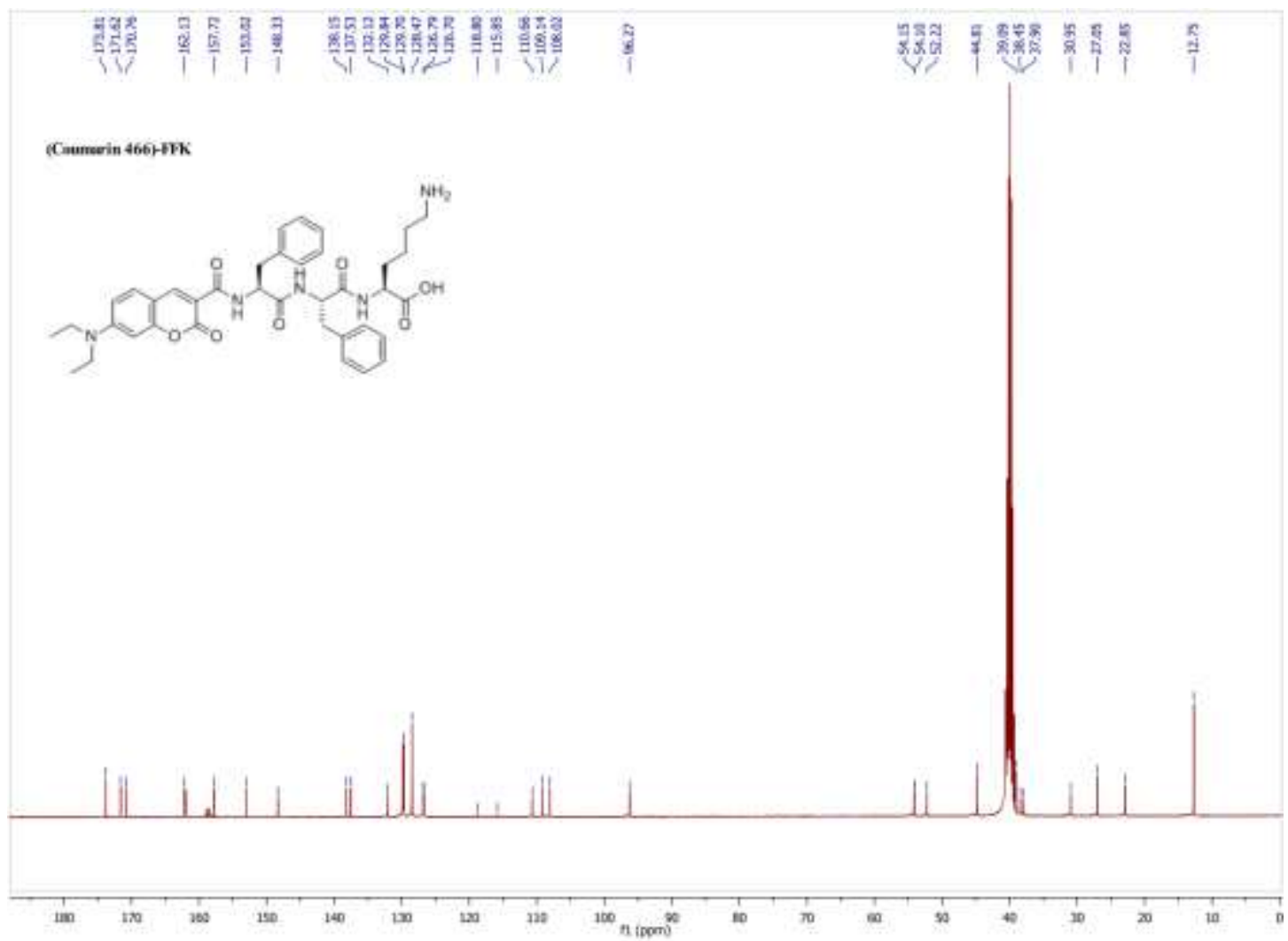

Figure S13. ${ }^{13} \mathrm{C}$ NMR spectrum of (Coumarin 466)-FFK. 


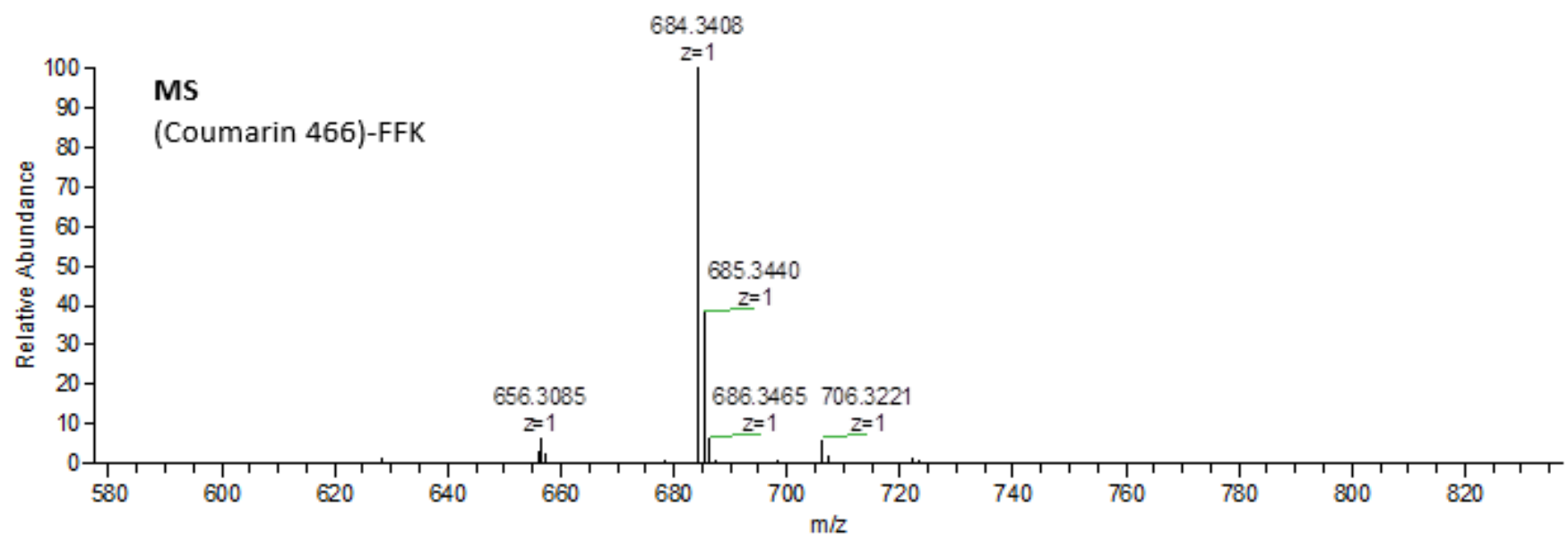

Figure S14. MS spectrum of (Coumarin 466)-FFK.

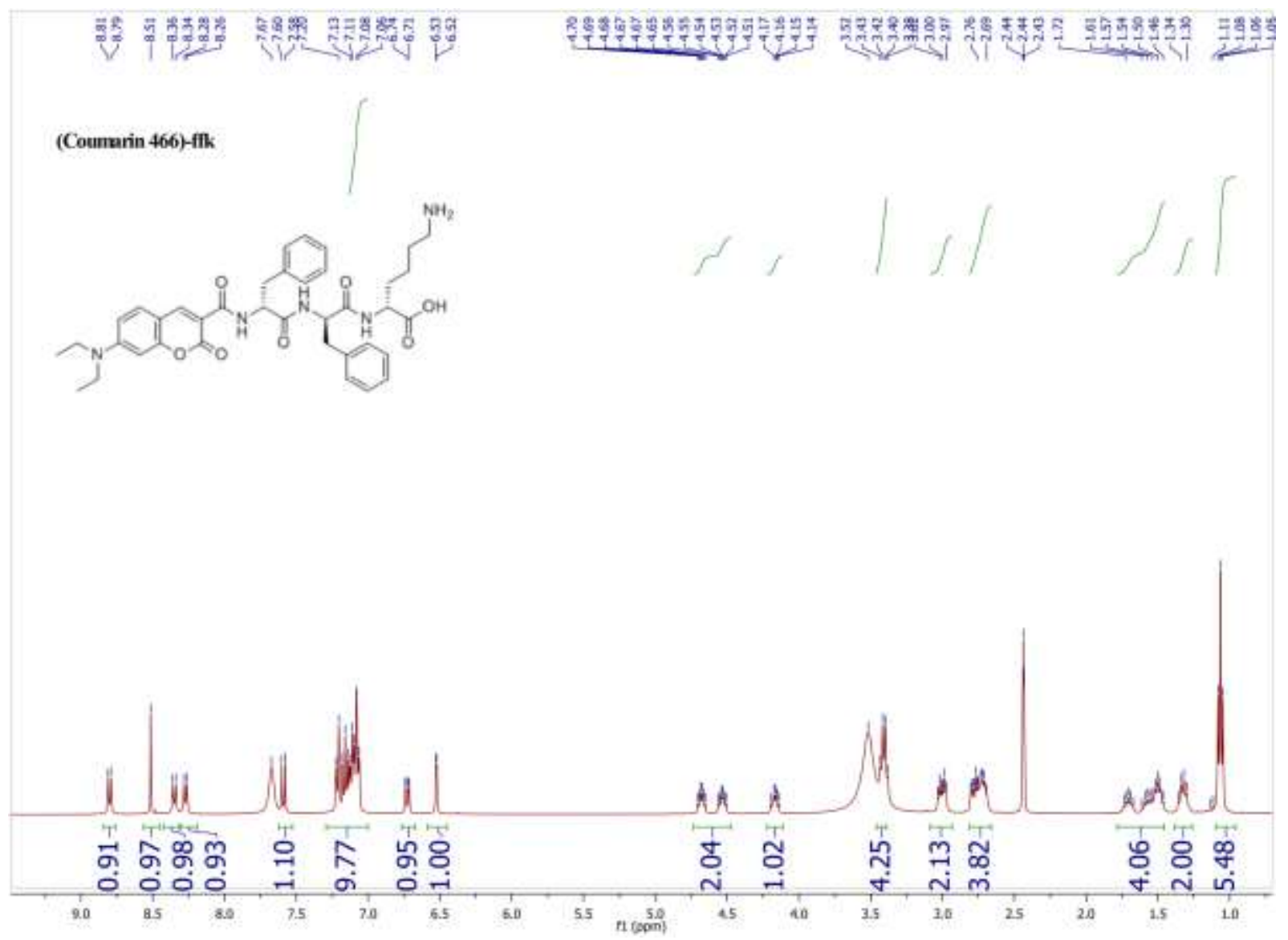

Figure S15. ${ }^{1} \mathrm{H}$ NMR spectrum of (Coumarin 466)-ffk. 


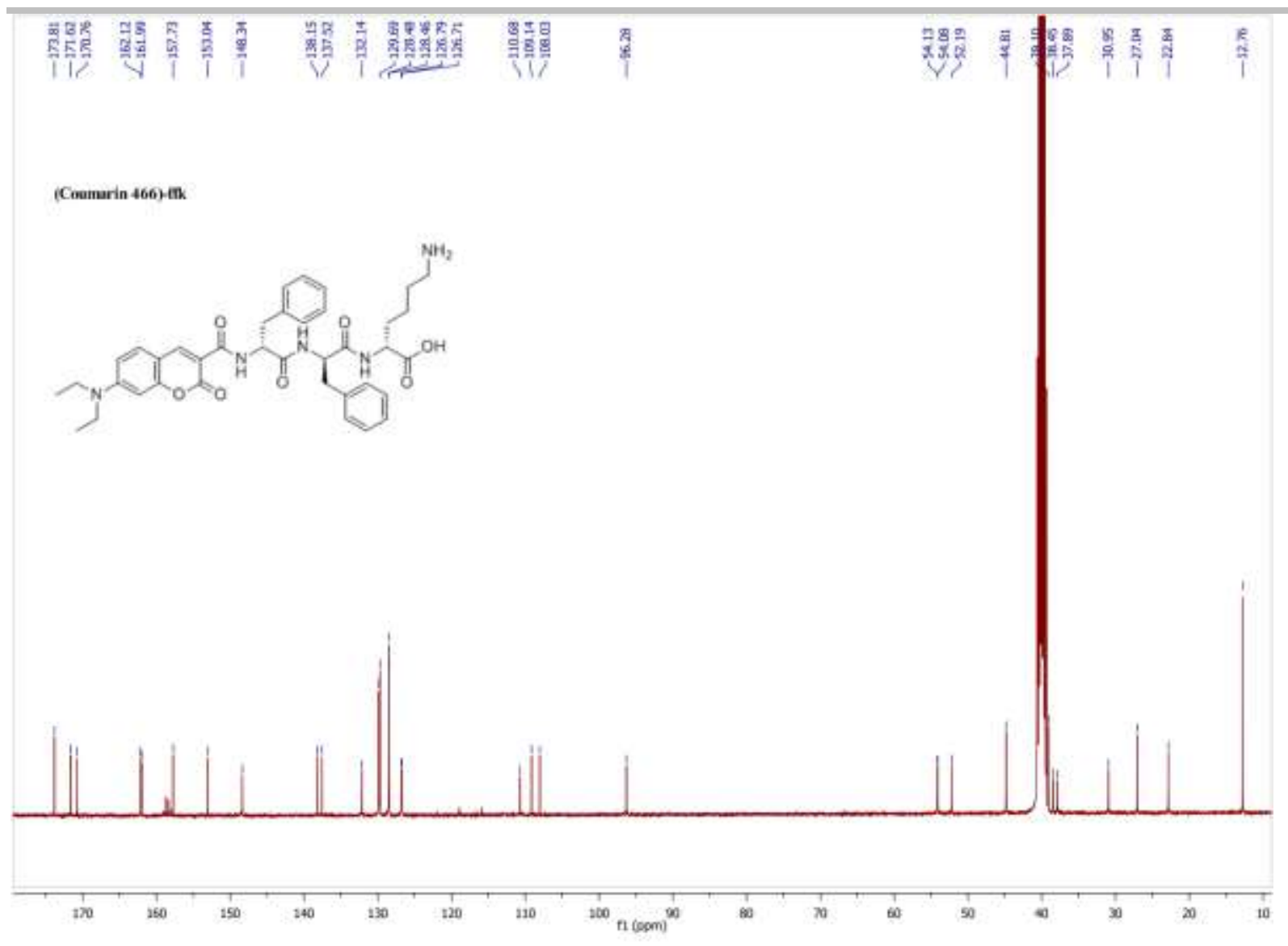

Figure S16. ${ }^{13} \mathrm{C}$ NMR spectrum of (Coumarin 466)-ffk.

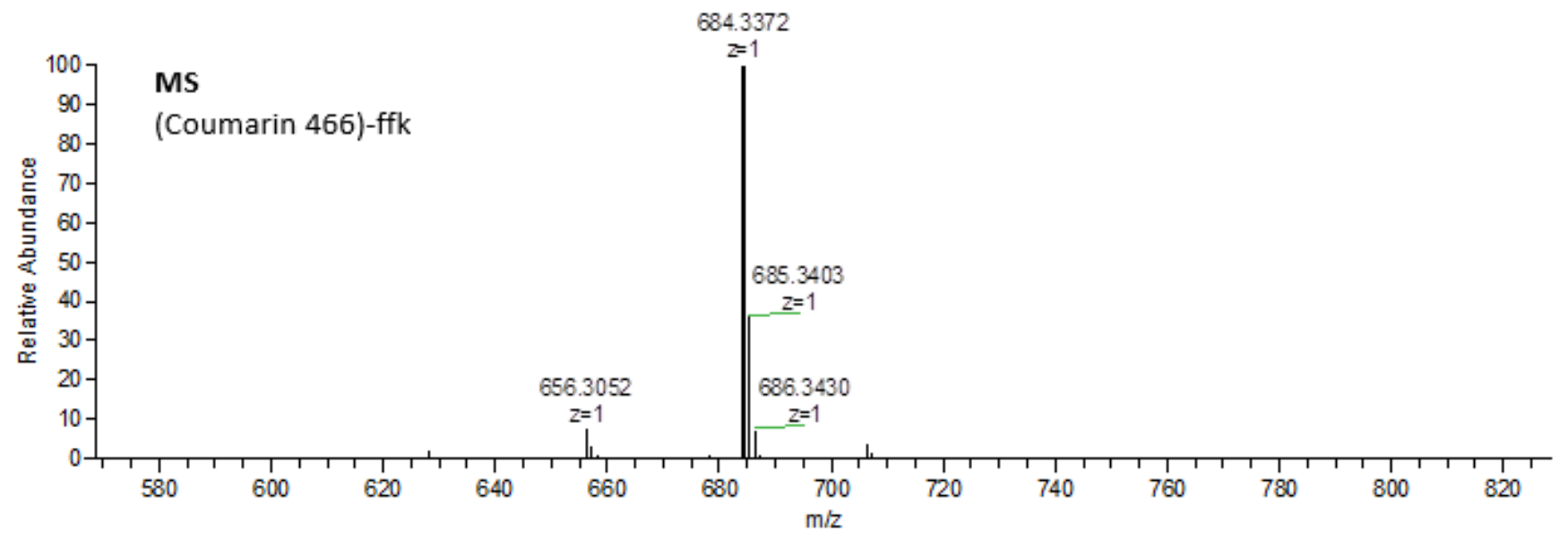

Figure S17. MS spectrum of (Coumarin 466)-ffk. 


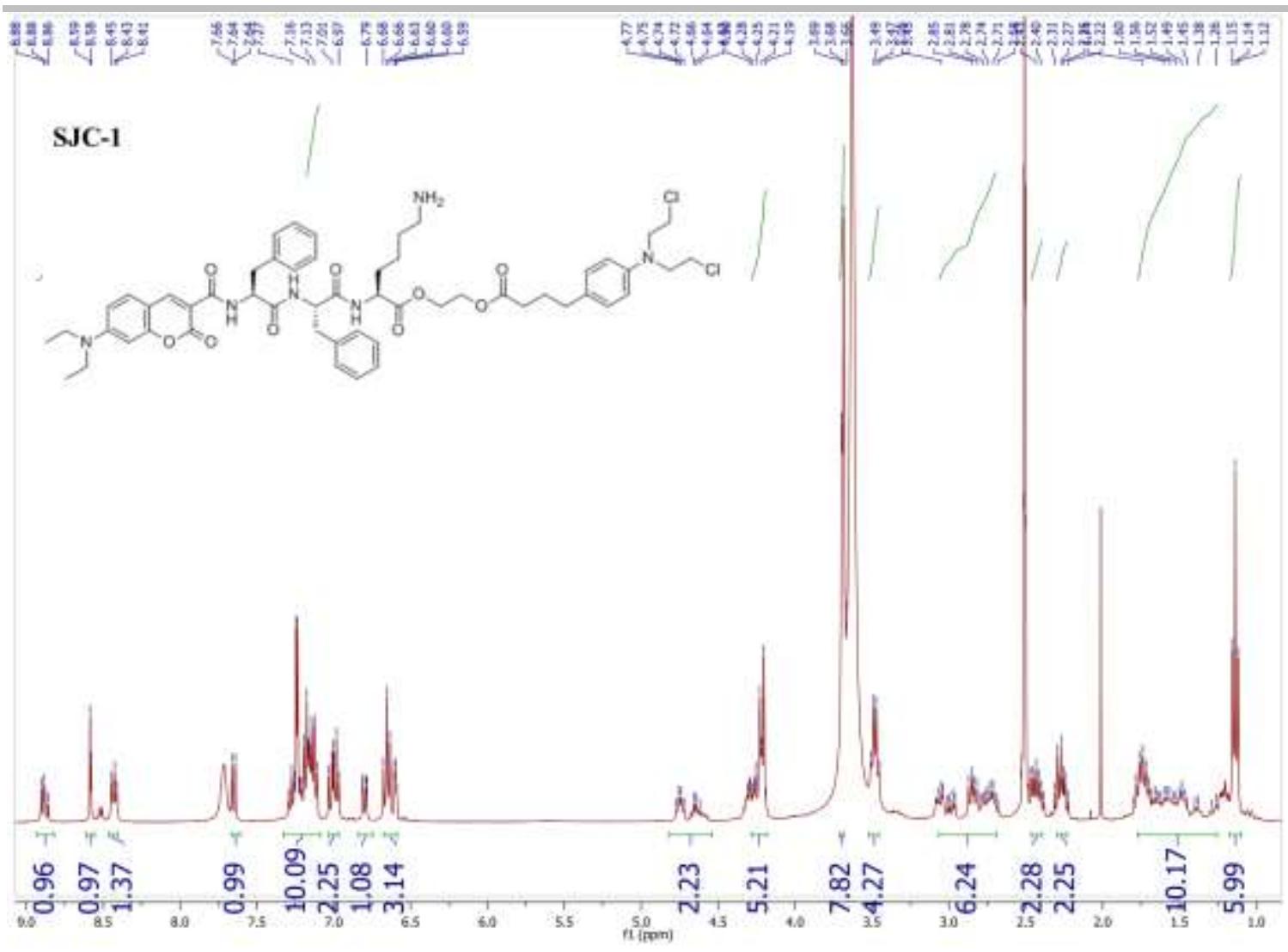

Figure S18. ${ }^{1} \mathrm{H}$ NMR spectrum of SJC-1

SJC-1<smiles>CCN(CC)c1ccc2cc(C(=O)NC(Cc3ccccc3)C(=O)N[C@@H](Cc3ccccc3)C(=O)NC(CCCCN)C(=O)OCCOC(=O)CCCc3ccc(N(CCCl)CCCl)cc3)c(=O)oc2c1</smiles>
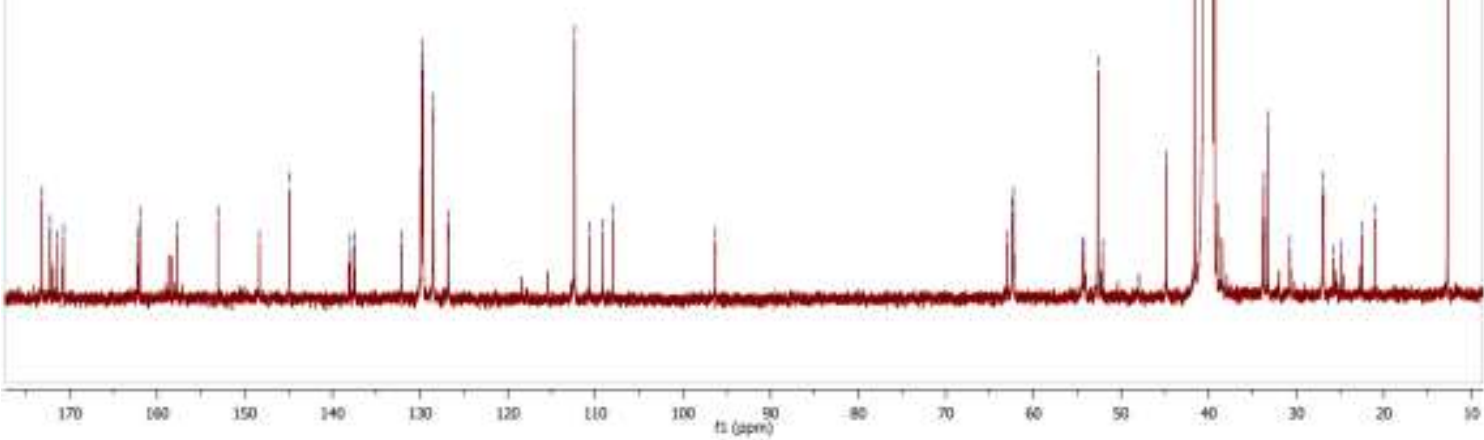

Figure S19. ${ }^{13} \mathrm{C}$ NMR spectrum of SJC-1. 


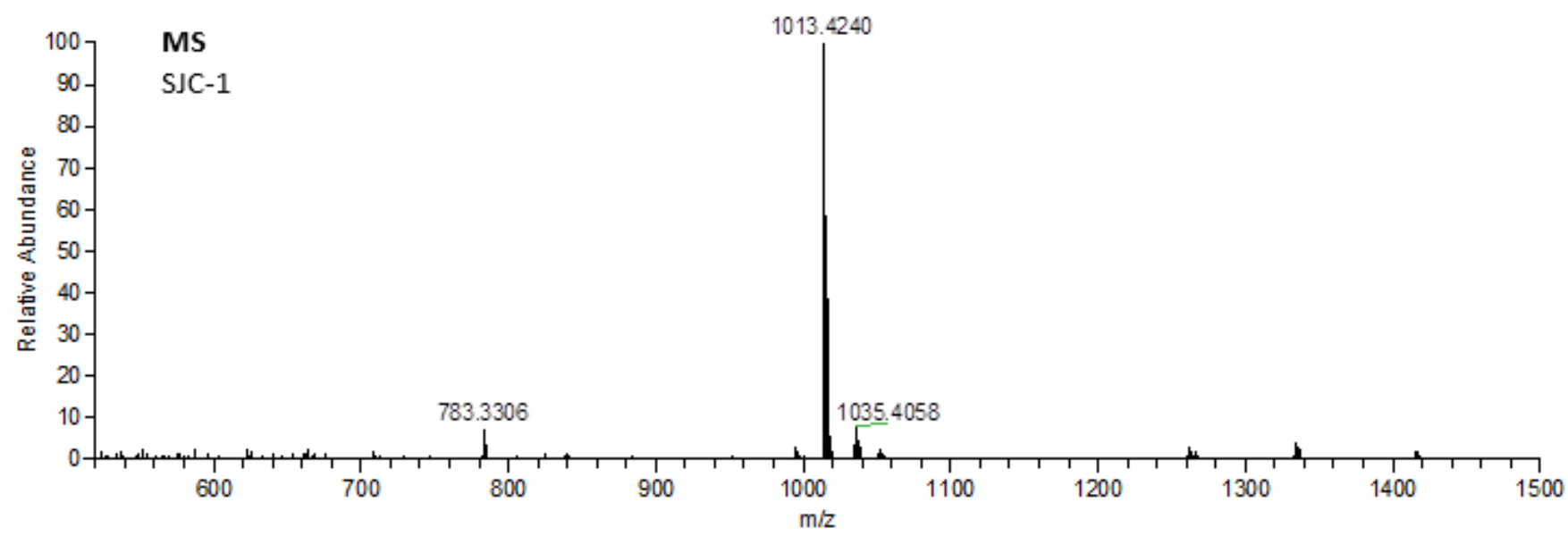

Figure S20. MS spectrum of SJC-1.

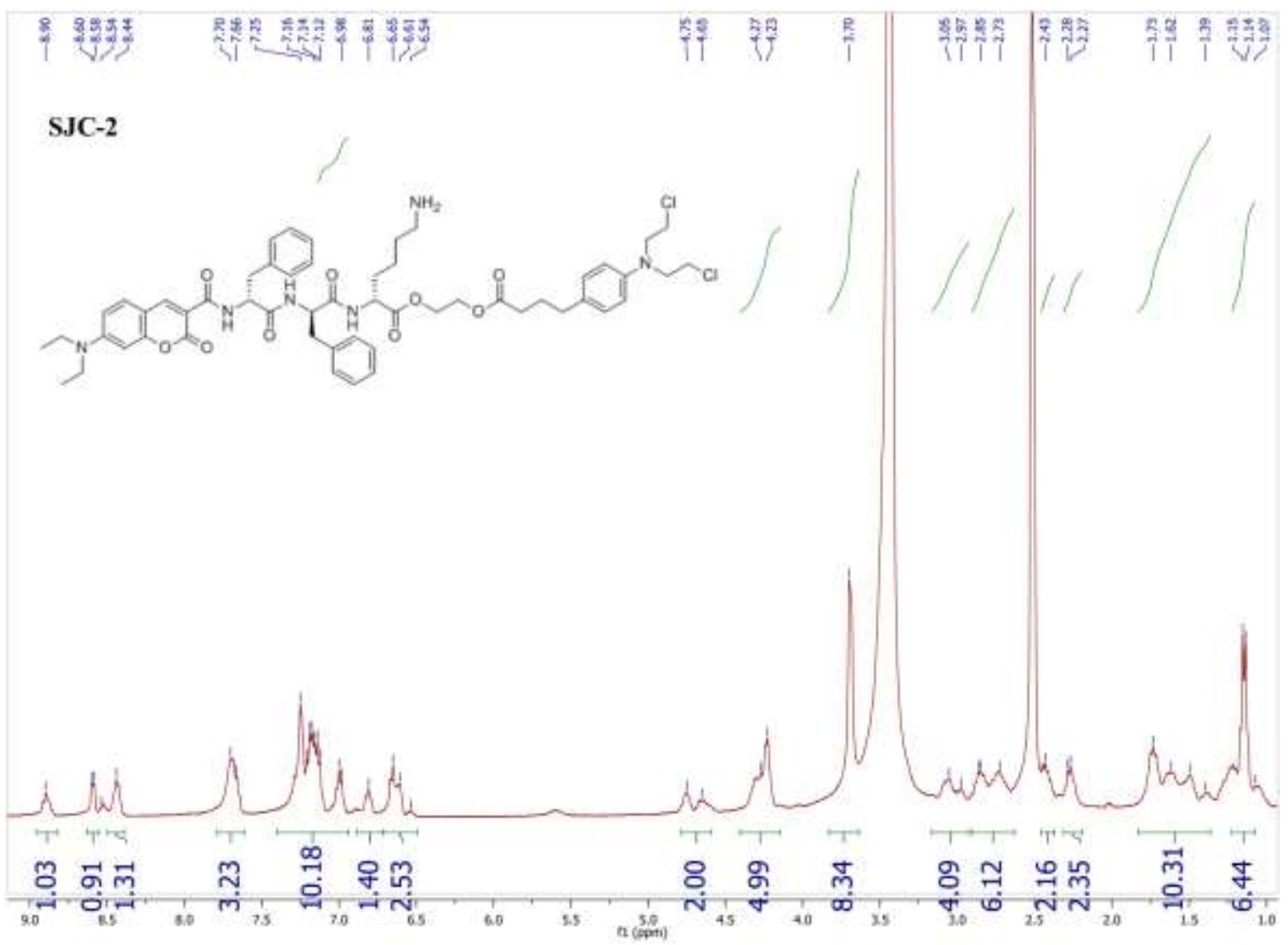

Figure S21. ${ }^{1} \mathrm{H}$ NMR spectrum of SJC-1. 


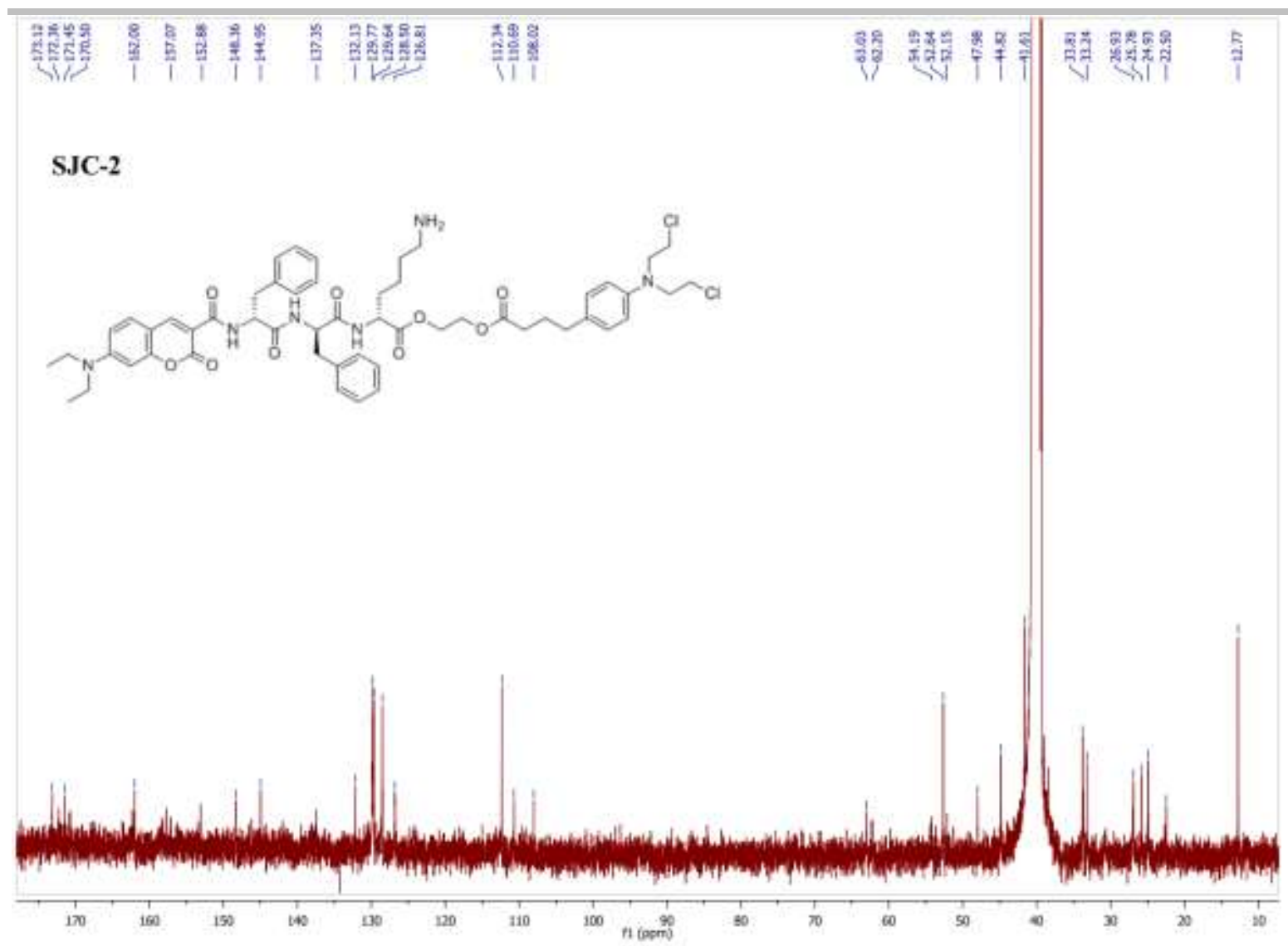

Figure S22. ${ }^{13} \mathrm{C}$ NMR spectrum of SJC-2.

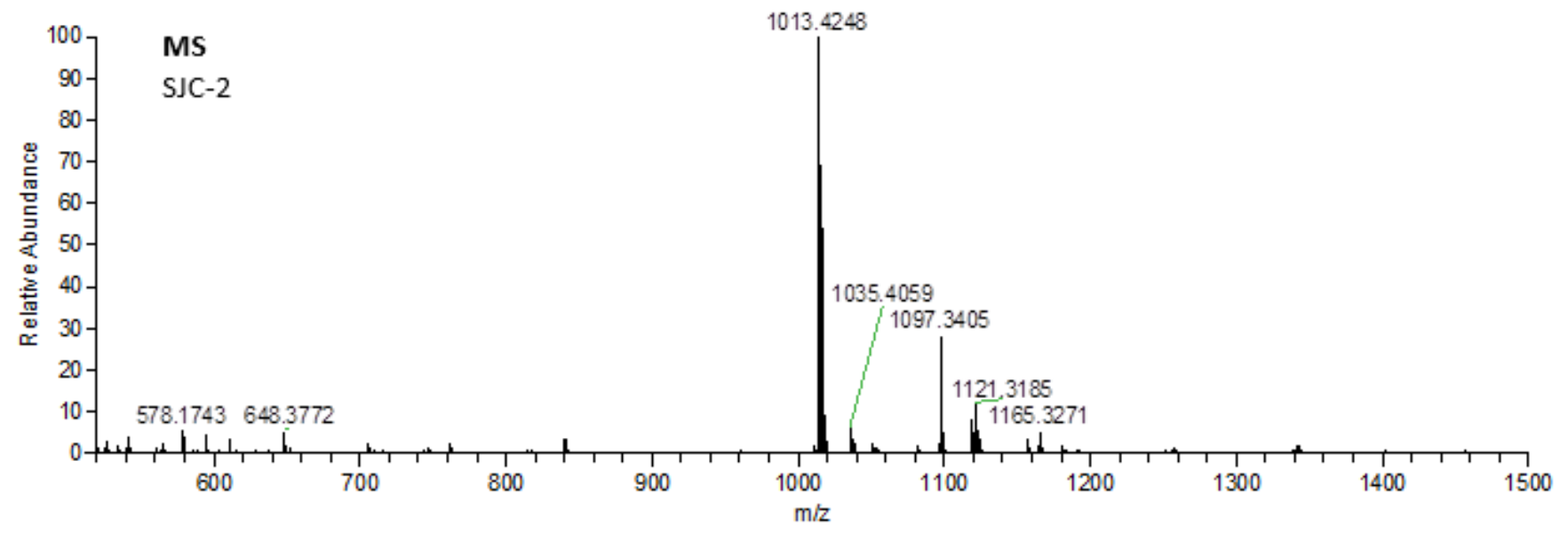

Figure S23. MS spectrum of SJC-2. 


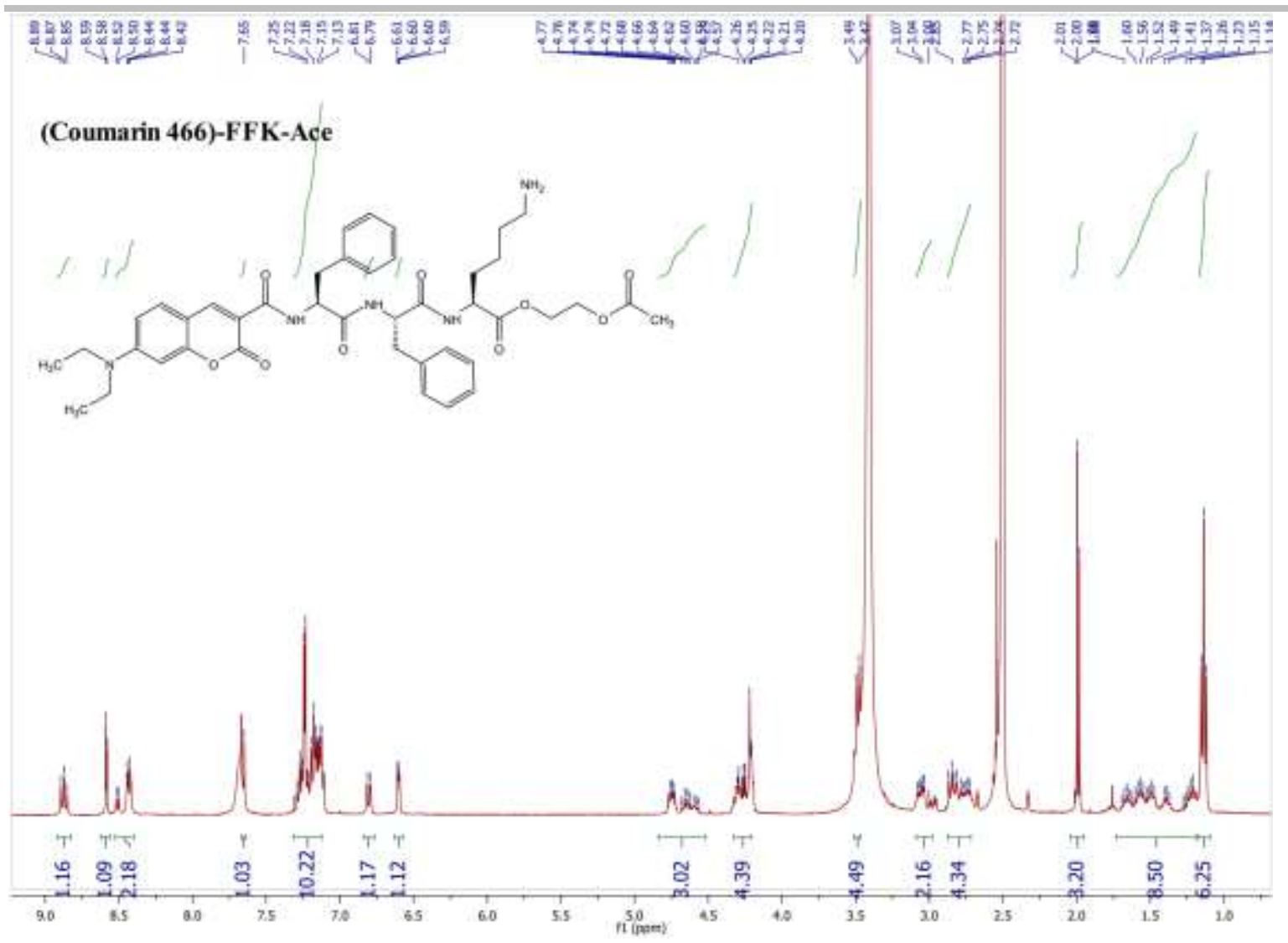

Figure S24. ${ }^{1} \mathrm{H}$ NMR spectrum of (Coumarin 466)-FFK-Ace.

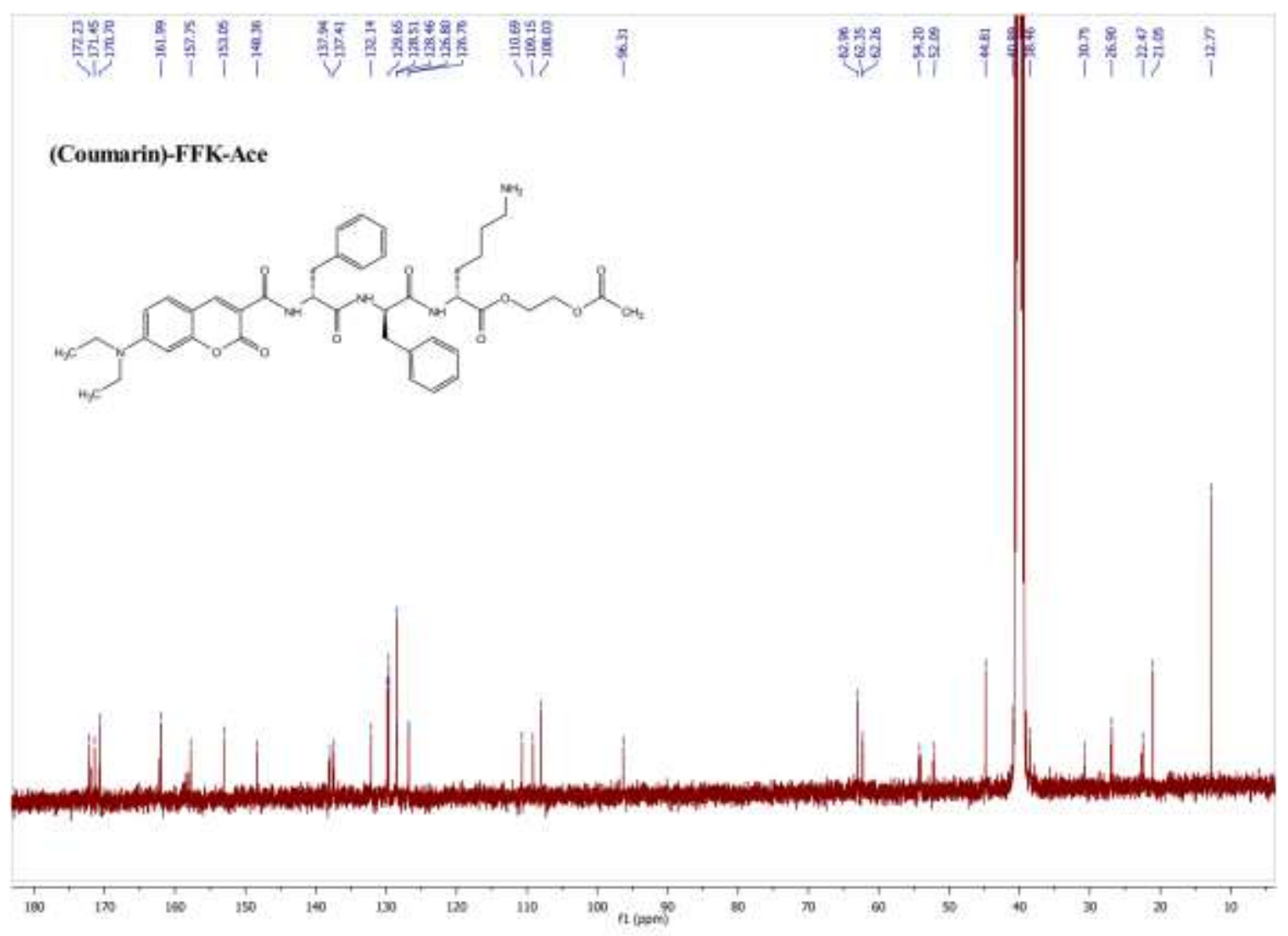

Figure S25. ${ }^{13} \mathrm{C}$ NMR spectrum of (Coumarin 466)-FFK-Ace 


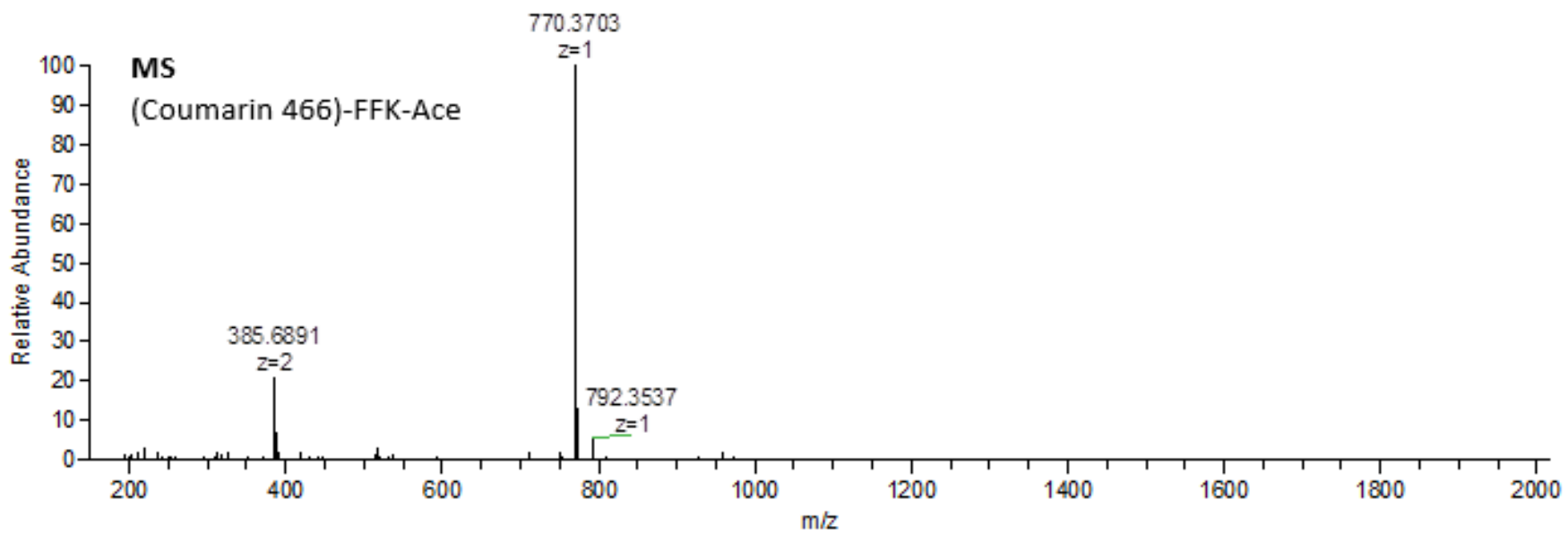

Figure S26. MS spectrum of (Coumarin 466)-FFK-Ace.

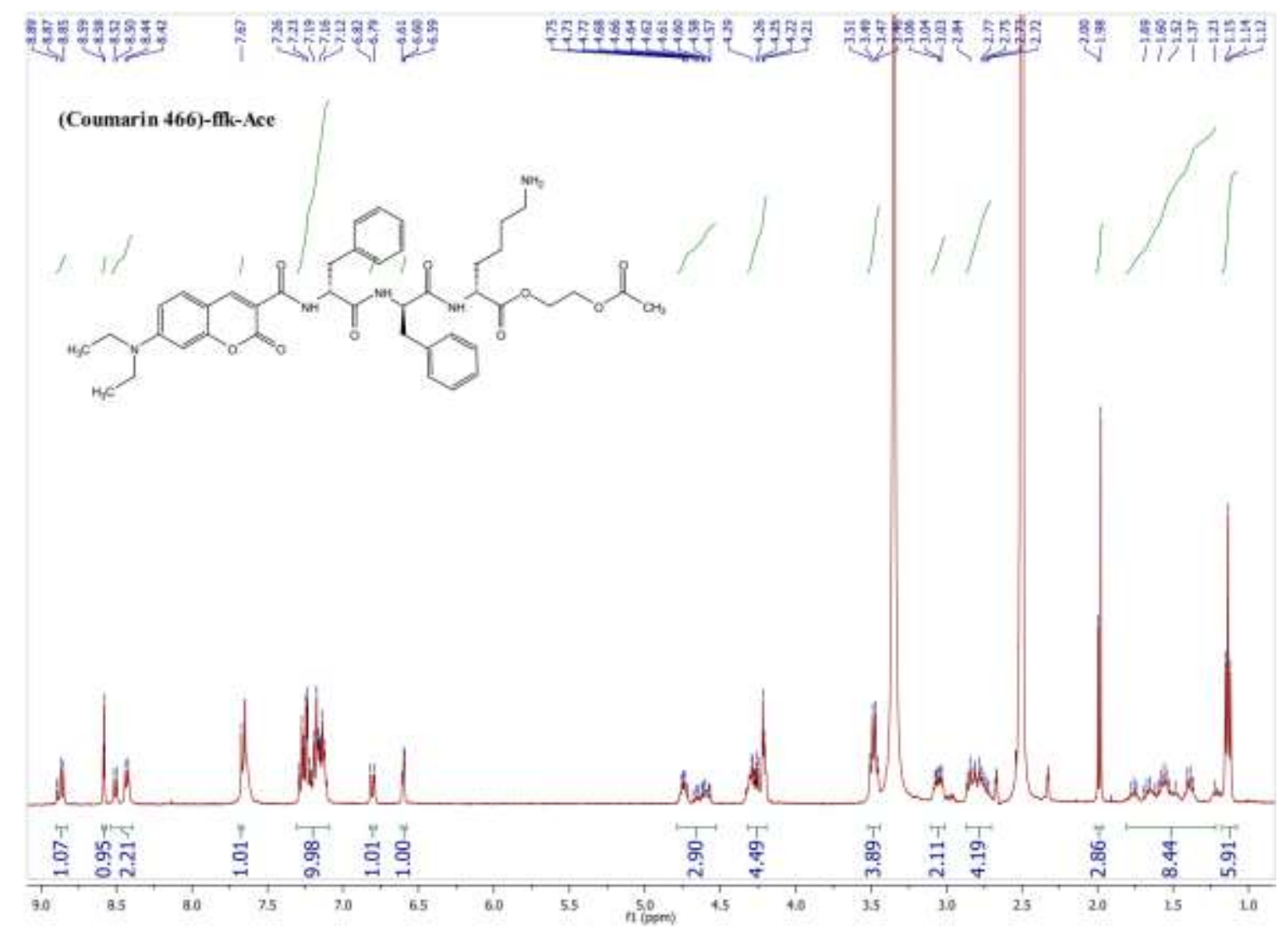

Figure S27. ${ }^{1} \mathrm{H}$ NMR spectrum of (Coumarin 466)-ffk-Ace. 


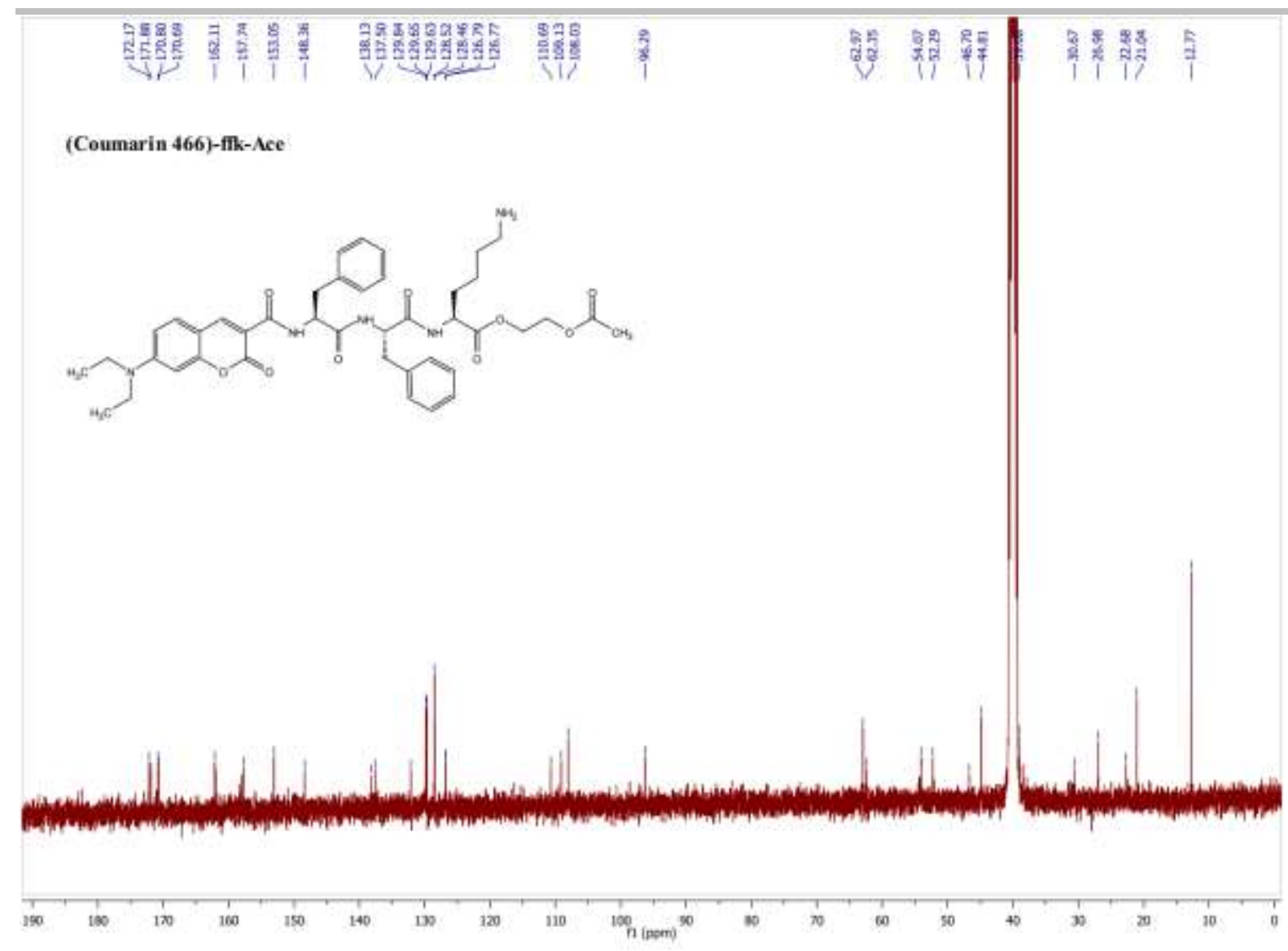

Figure S28. ${ }^{13} \mathrm{C}$ NMR spectrum of (Coumarin 466)-ffk-Ace.

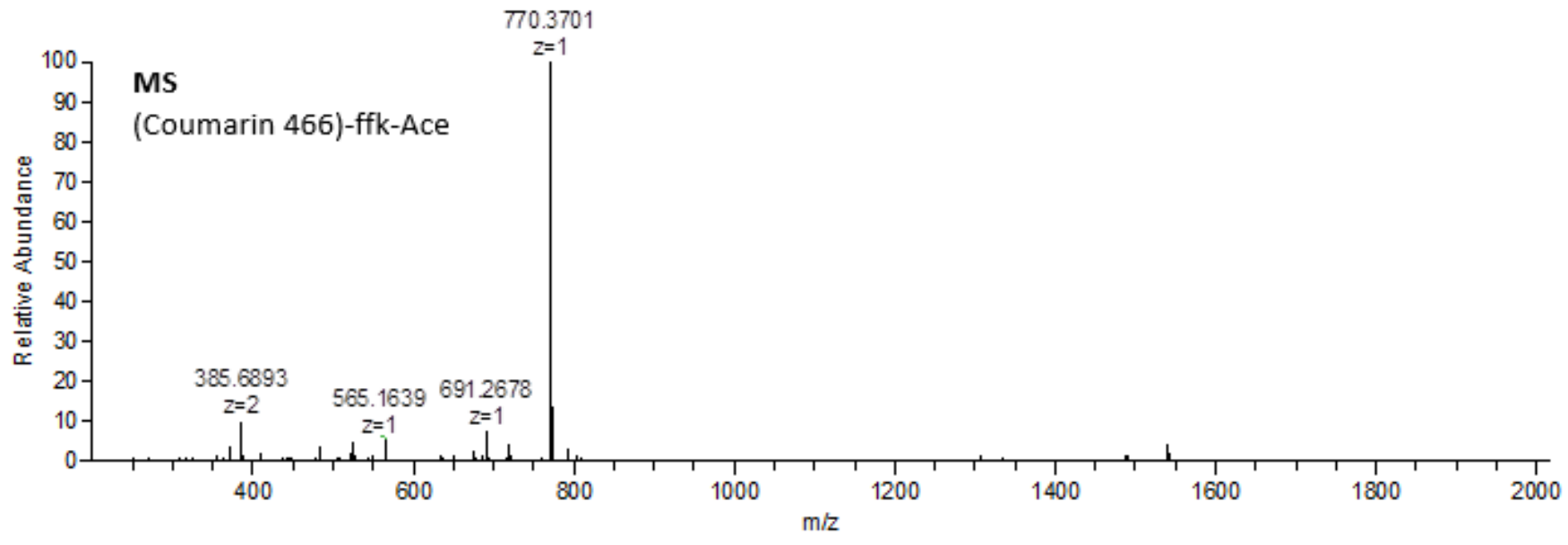

Figure S29. MS spectrum of (Coumarin 466)-ffk-Ace 